\title{
Orographic cirrus in a future climate
}

\author{
H. Joos, P. Spichtinger, and U. Lohmann \\ Institute for Atmospheric and Climate Science, ETH Zurich, Universitaetsstrasse 16, 8092 Zurich, Switzerland
}

Received: 11 March 2009 - Published in Atmos. Chem. Phys. Discuss.: 3 April 2009

Revised: 4 September 2009 - Accepted: 22 September 2009 - Published: 20 October 2009

\begin{abstract}
A cloud resolving model (CRM) is used to investigate the formation of orographic cirrus clouds in the current and future climate. The formation of cirrus clouds depends on a variety of dynamical and thermodynamical processes, which act on different scales. First, the capability of the CRM in realistically simulating orographic cirrus clouds has been tested by comparing the simulated results to aircraft measurements of an orographic cirrus cloud. The influence of a warmer climate on the microphysical and optical properties of cirrus clouds has been investigated by initializing the CRM with vertical profiles of horizontal wind, potential temperature and equivalent potential temperature, respectively. The vertical profiles are extracted from IPCC A1B simulations for the current climate and for the period 2090-2099 for two regions representative for North and South America. The influence of additional moisture in a future climate on the propagation of gravity waves and the formation of orographic cirrus could be estimated. In a future climate, the increase in moisture dampens the vertical propagation of gravity waves and the occurring vertical velocities in the moist simulations. Together with higher temperatures fewer ice crystals nucleate homogeneously. Assuming that the relative humidity does not change in a warmer climate the specific humidity in the model is increased. This increase in specific humidity in a warmer climate results in a higher ice water content. The net effect of a reduced ice crystal number concentration and a higher ice water content is an increased optical depth. However, in some moist simulations dynamical changes contribute to changes in the ice water content, ice crystal number concentration and optical depth. For the corresponding dry simulations dynamical changes are more pronounced leading to a decreased optical depth in a future climate in some cases.
\end{abstract}

Correspondence to: H. Joos

(hanna.joos@env.ethz.ch)

\section{Introduction}

Cirrus clouds have a strong influence on the radiative budget of the earth. They can either cool or warm the EarthAtmosphere system depending on their microphysical properties like ice water content or ice crystal number concentration. Generally, optically thick cirrus clouds exert a cooling effect and optically thin clouds a warming effect. The global net effect of cirrus clouds tends to warm the EarthAtmosphere-system (Chen et al., 2000). Our understanding of the formation of cirrus clouds and their resulting microphysical and optical properties is crucial to predict changes in the radiative budget in the future climate. However, as the formation of cirrus clouds depends on very complex multiscale dynamical and microphysical processes, their formation and life cycle is not well known (Spichtinger et al., 2005a,b). A significant part of the uncertainties in the prediction of future climate in general circulation models (GCM) arises from the representation of cirrus cloud formation (Zhang et al., 2005). As in most GCMs only large scale vertical velocities are calculated and the manifold dynamical processes which strongly influence the formation of cirrus are not taken into account, the cirrus cloud amount is underestimated in many GCMs and no reliable prediction of a change in cirrus cloud cover is possible as the correct underlying physical process is not taken into account. There are only two parameterizations for GCMs (the HadAM3 and the ECHAM5 model) available which at least take the formation of orographic cirrus clouds into account (Dean et al., 2005; Joos et al., 2008). Additionally, anthropogenic aerosols can change the ice crystal number concentration and exert an anthropogenic forcing comparable to the forcing on warm clouds (Penner et al., 2009). An estimation of the influence of a changing climate on the formation of (orographic) cirrus and the radiative budget is still difficult.

In order to estimate the changes in orographic cirrus cloud cover in a warmer climate, it is necessary to determine the

Published by Copernicus Publications on behalf of the European Geosciences Union. 
key processes, which influence the formation of orographic cirrus. Here, changes in the flow regime due to a change in atmospheric stability caused by a change in the temperature and moisture profiles, an increase of horizontal wind speed especially in the upper troposphere and, of course, the changes due to warmer temperatures have to be taken into account. There are several studies describing the influence of moisture on the propagation of orographically excited gravity waves (see e.g. Durran and Klemp (1983); Jiang (2003)). The additional moisture weakens the atmospheric stability and amplitudes of the gravity waves and thus the vertical velocities which strongly influence the ice crystal number concentration. Additionally, the vertical wavelength is increased. On the other hand, the increase in horizontal wind speed leads to an increase of the amplitudes and vertical velocities of the waves. In order to investigate the impact of these two opposing effects, which we expect in a changing climate, we present simulations with the non-hydrostatic anelastic model EULAG (Prusa et al., 2008). As in this model a detailed ice microphysical scheme is implemented (Spichtinger and Gierens, 2009) it can be used in order to assess the dynamical and thermodynamical changes in a future climate and its influence on the formation of orographic cirrus clouds.

In order to determine the importance of the individual processes, idealized simulations were carried out where changes in the temperature profiles, the relative humidity with respect to ice (RHi) and the position of the ice supersaturated layer have been investigated. In order to determine the changes in the microphysical and optical properties of orographic cirrus in a future climate, simulations initialized with vertical profiles taken from IPCC simulations for the beginning and the end of the 21 st century were performed.

In Sect. 2 the model used for this study is introduced briefly. In Sect. 3 we show the model's capability to simulate realistic orographic cirrus by comparing the results of a simulation with in situ aircraft measurements. In Sect. 4 we present results of idealized simulations and discuss them and in Sect. 5 the results of the simulations initialized with IPCC profiles are presented. In Sect. 6 we summarize our work and draw some conclusions.

\section{Model description}

For this study we use the anelastic, non-hydrostatic model EULAG (Smolarkiewicz and Margolin, 1997; Prusa et al., 2008; Grabowski and Smolarkiewicz, 2002). In the standard version of the model used for this study, a two-moment bulk ice microphysics scheme is implemented and "moist" dynamics and a coupling of dynamics and thermodynamics is performed.

In the ice-microphysics scheme the ice classes correspond to different nucleation processes (homogeneous and heterogeneous freezing) and include the processes of ice crystal nucleation, depositional growth/evaporation and sedimenta- tion. In our simulations only homogeneous freezing is considered as it can be assumed that the formation of orographic cirrus is dominated by high vertical velocities and supersaturations and that homogeneous freezing is the dominant freezing mechanism (Kärcher and Ström, 2003). The homogeneous nucleation rate is parameterized according to Koop et al. (2000). The background aerosol (sulfuric acid) is distributed log-normally with a modal radius $r_{m}=25 \mathrm{~nm}$ for aqueous solution droplets and geometric standard deviation $\sigma=1.4$. In Spichtinger and Gierens (2009) it was found that this setup gives reliable results for homogeneous nucleation events. For a more detailed description of the ice microphysics scheme see Spichtinger and Gierens (2009). For all simulations shown in this study, a 2-dimensional ( $\mathrm{x}-\mathrm{z}$ plane) model domain is used. The detailed model setup for each simulation is described at the beginning of every chapter.

\section{Model verification: simulation of the INCA-case}

In order to show the model's capability to represent the formation of orographic cirrus clouds, measurements from the INCA (Interhemispheric differences in cirrus properties from anthropogenic emissions) campaign (Gayet et al., 2004) are used as comparison. The INCA-campaign took place in April 2000 over Punta Arenas, Chile and in October 2000 over Prestwick, Scotland, respectively. The measurements used for this comparison were taken on the 5th of April 2000 between 18:00 and 19:00 UTC on a flight track at $53^{\circ} \mathrm{S}$ from $69.2^{\circ} \mathrm{W}$ to $76^{\circ} \mathrm{W}$. During this flight, the vertical velocity, ice crystal number concentration and ice water content in an orographic cloud were measured. Vertical velocities were measured with a five-hole probe only during constant altitude flight sections. The accuracy of the vertical velocity is estimated to be on the order of $0.1 \mathrm{~m} \mathrm{~s}^{-1}$ (Bögel and Baumann, 1991). Ice particle concentrations were measured with a combination of two instruments, the FSSP-300 and 2DC-C optical probe onboard the DLR Falcon (Gayet et al., 2002, 2004). The particle concentrations used for this comparison refer to the particle size range 3-800 micrometer in diameter. Furthermore, residual particle measurement with the Counterflow Virtual Impactor, CVI (Noone et al., 1993) have been carried out.

In order to test the model's capability to represent orographic cirrus clouds in a correct way, these measurements are compared to a 2-dimensional simulation with the EULAG model. As initial profiles we used the temperature and wind data from the ECMWF (European Centre for MediumRange Weather Forecasts) Reanalyse data for the 5th of April 2000 at 18:00 UTC when the measurements were taken. Additionally, a realistic topography from the National Geographical Data Centre (NGDC, Hastings et al. (1999)) is implemented. Figure 1 shows the initial profiles of temperature $T(z)$, potential temperature $\theta(z)$, horizontal wind speed $u(z)$ and pressure $p(z)$, respectively. The wind direction is 

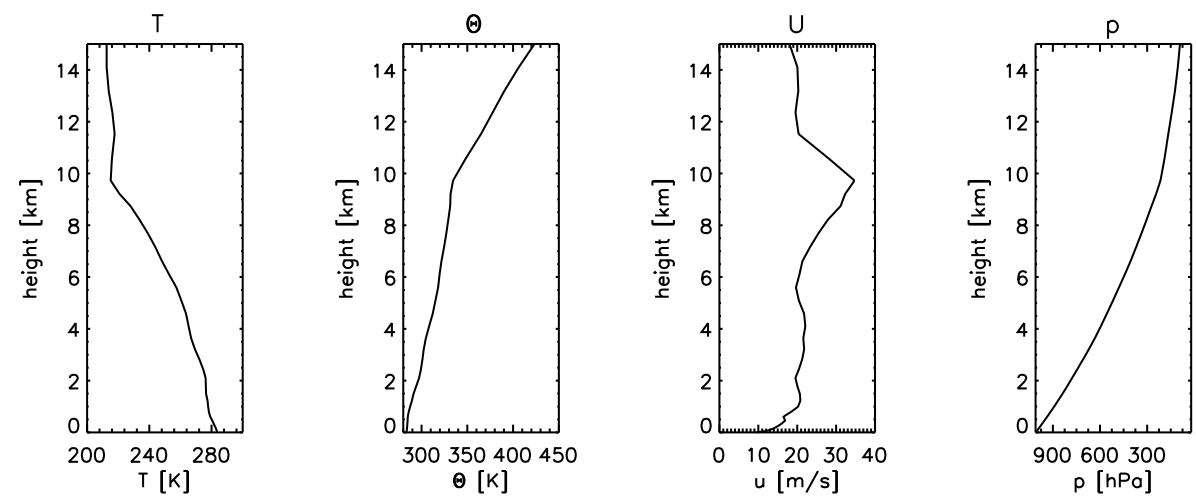

Fig. 1. Initial vertical profiles of temperature $T$, potential temperature $\theta$, horizontal wind speed $u$ and pressure $p$ taken from the ECMWF Reanalyse data for the 5th of April 2000 at 18:00 UTC at $53^{\circ} \mathrm{S}$ and $78^{\circ} \mathrm{W}$.

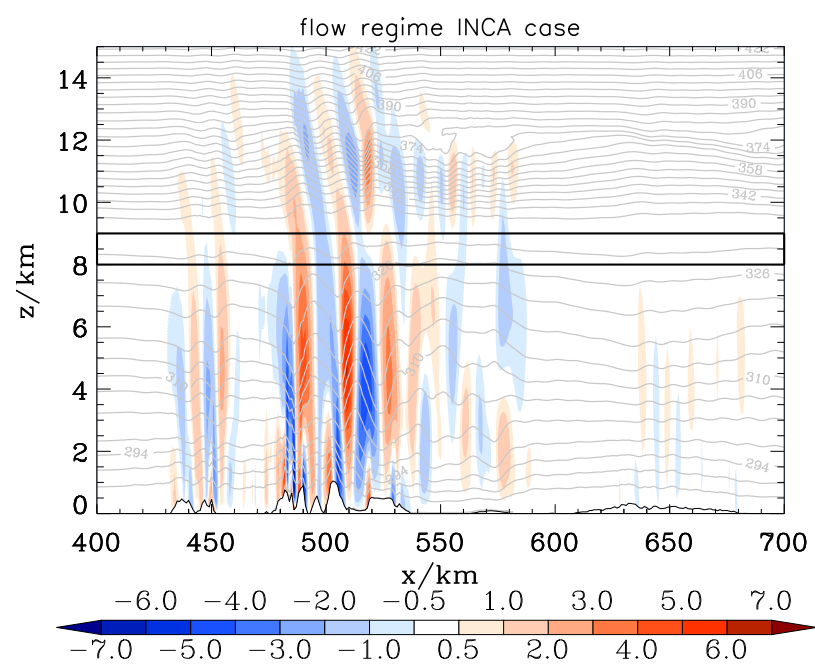

Fig. 2. Flow regime for the INCA case on the 5th of April 2000, 18:00 UTC initialized with the ECMWF profiles. Grey lines denote lines of constant potential temperature and the colorbar indicates the vertical velocity in $\mathrm{ms}^{-1}$. The black box shows the position of the supersaturated layer.

approximately $260^{\circ}$. For simplicity we assumed a pure west wind here.

In this simulation we used a horizontal model domain of $1000 \mathrm{~km}$ and $20 \mathrm{~km}$ in the vertical with a horizontal resolution $\mathrm{dz}=1000 \mathrm{~m}$ and a vertical resolution $\mathrm{dz}=50 \mathrm{~m}$. In all simulations the dynamical time step is $d t=2.5 \mathrm{~s}$ and the microphysical time step is $d t_{m}=d t / 10=0.25 \mathrm{~s}$. The model is run for $5 \mathrm{~h}$. In all simulations the Coriolis force is neglected. Figure 2 shows the result of the flow over the realistic topography initialized with the ECMWF profiles after $t=5 \mathrm{~h}$.

The topography of the Andes induces gravity waves that propagate through the whole troposphere. The maximum and minimum vertical velocities amount to $+8 /-8 \mathrm{~m} \mathrm{~s}^{-1}$, re- spectively. They occur in a height between 4 and $6 \mathrm{~km}$. According to the height of the flight, an ice supersaturated region (ISSR) has been implemented in a height of 8500 $9500 \mathrm{~m}$ with an initial supersaturation of $\mathrm{RHi}=130 \%$. In order to compare the simulation with the measurements, histograms for the vertical velocity, ice crystal number concentration (ICNC) and ice water content (IWC) are shown. The temperatures measured during the flight lie between $230 \mathrm{~K}$ and $226 \mathrm{~K}$. Therefore, we selected the simulated values at $T=226 \mathrm{~K}$ and $T=230 \mathrm{~K}$ for comparison. Additionally, the distribution sampled over the whole ISSR is shown. The simulated values sampled over the 5 simulated hours are shown in Fig. 3.

It can be seen that the model reproduces the distribution of the measured variables remarkably well. The measured vertical velocity is in the range between +1.8 and $-1.8 \mathrm{~m} \mathrm{~s}^{-1}$. In general, this can be reproduced well although the model seems to overestimate the vertical velocities. This is due to the 2-dimensional setup that leads to an overestimation of the vertical velocity (Dörnbrack, 1998) and the effect of moisture on the propagation of gravity waves, which would lead to a decrease in vertical velocities. This is neglected here. On the other hand, as the airplane flies with $\sim 170 \mathrm{~m} \mathrm{~s}^{-1}$ it did not necessarily reach to measure the highest occuring velocities. If all these restrictions are taken into account, one can say that the model is quite able to represent the measured values (see Fig. 3). The results for the ICNC and IWC also agree very well with the observation. Gayet et al. (2006) stated that shattering of ice crystals leading to an overestimation of measured ICNC was unlikely as different techniques were used. The comparison of the results obtained with the different techniques showed little difference such that shattering can be ruled out for this case. Based on these results, we assume that the model is able to simulate realistic vertical velocities and microphysical properties of orographic cirrus clouds and can thus be used for further investigations of orographic cirrus clouds with idealized simulations as described in the next 

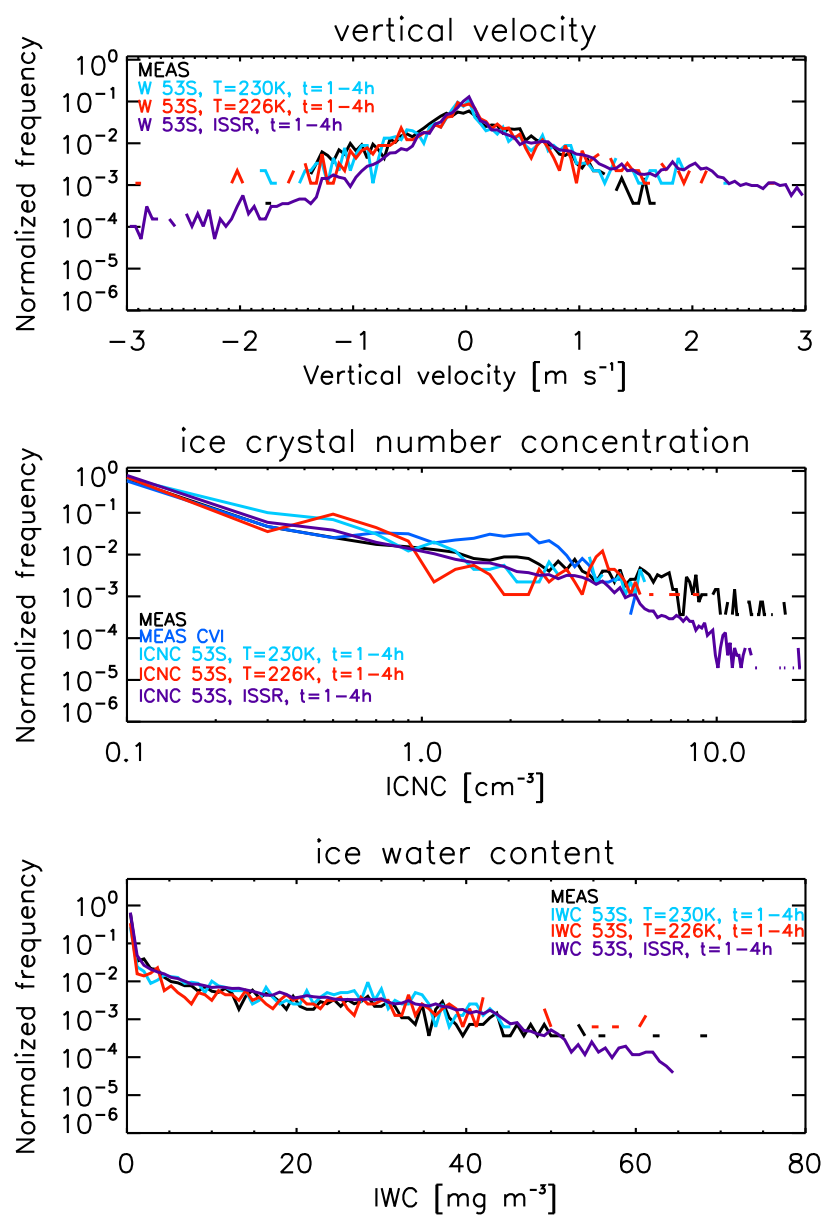

Fig. 3. Comparison of the simulated and measured vertical velocity (upper panel), ICNC (middle panel) and ice water content (lower panel). For the ICNC the black line denotes the combined measurements taken with the FSSP-300 and 2DC-C optical probe. Additionally, the measurements with the CVI are shown in dark blue. The simulated results for the temperature range $226 \mathrm{~K}$ and $230 \mathrm{~K}$ are shown in red and light blue, respectively. The purple line shows the simulated results sampled over the whole ISSR. All simulated values contain data sampled over all time steps.

chapter or to investigate the changes in microphysical properties in a changing climate as discussed in chapter 5 .

\section{Idealized simulations}

To investigate the key parameters, which determine the microphysical and optical properties of orographic cirrus clouds in a future climate, idealized simulations have been carried out. In a future climate, there are two main processes, which influence the properties of an orographic cirrus cloud. On the one hand, an increase in moisture could lead to a damping of the gravity waves amplitude and reduce the vertical velocities. Furthermore, the vertical wavelength could in- crease such that the ISSR shifts in a different vertical phase of the wave. On the other hand, the temperature increase changes the available water vapor under the assumption of a constant relative humidity and has an influence on the depositional growth. In order to assess the importance of these individual thermodynamical and dynamical processes and its influence on the formation of cirrus clouds, the temperature inside the ISSR has been changed and the height of the ISSR is shifted to a lower/higher position such that a change in the wave phase is simulated.

The model is initialized with the ambient potential temperature and pressure profiles $\theta(z)$ and $p(z)$ according to Clark and Farley (1984), using a constant Brunt-Väisäla frequency $N$ over the whole troposphere. From $\theta(z)$ and $p(z)$ the physical temperature $T(z)$ and the density $\rho(z)$ can be calculated. Additionally, a wind profile $u(z)$ is prescribed: between 0 and $2 \mathrm{~km}$ height, $u(z)$ increases from $4 \mathrm{~m} \mathrm{~s}^{-1}$ to $9 \mathrm{~m} \mathrm{~s}^{-1}$. From $2 \mathrm{~km}$ to $12 \mathrm{~km}$ the horizontal velocity is constant $\left(u(z)=9 \mathrm{~m} \mathrm{~s}^{-1}\right)$. Above that level it decreases linearly until $u(z=15 \mathrm{~km})=-10 \mathrm{~m} \mathrm{~s}^{-1}$. For these simulations we use a 2-D domain (x-z-plane) with a horizontal extension of $320 \mathrm{~km}$ and a vertical extension of $20 \mathrm{~km}$ with a bell shaped mountain in the middle of the domain. The mountain shape can be described as

$H(x)=\frac{h_{0}}{1+\frac{x^{2}}{a^{2}}}$

where $a=10000 \mathrm{~m}$ is the half-width of the mountain and $h_{0}=600 \mathrm{~m}$ the maximum height, respectively. The nondimensional mountain height is given by $\hat{h}=N h_{0} / u=0.6$ which leads to a hydrostatic mountain wave. The horizontal and vertical resolutions are $d x=250 \mathrm{~m}$ and $d z=50 \mathrm{~m}$, respectively. The simulations have been carried out for $5 \mathrm{~h}$. An ice supersaturated layer (ISSR) with a depth of $1 \mathrm{~km}$ has been implemented in the model additionally.

First, a reference case has been defined: The ISSR is situated in the vertical range between $8500 \mathrm{~m}$ and $9500 \mathrm{~m}$. This corresponds to the height where the highest vertical velocity in the developing hydrostatic wave occurs. The initial temperature profile has been chosen in a way that the temperature in the middle of the reference ISSR is $220 \mathrm{~K}$ and the reference initial supersaturation with respect to ice (RHi) is $120 \%$. Then two different effects were investigated.

1. A shift of the initial $\theta$ profiles such that the temperature in the middle of the reference ISSR is $210 \mathrm{~K}$ and $230 \mathrm{~K}$, respectively (see Fig. 4).

2. A change of the height of the ISSR, which causes a different temperature and a different position in the wave phase. The height of the ISSR has been shifted so that the temperature in the middle of the lowest layer is $230 \mathrm{~K}$ and in the highest layer $210 \mathrm{~K}$ (see Fig. 5). 

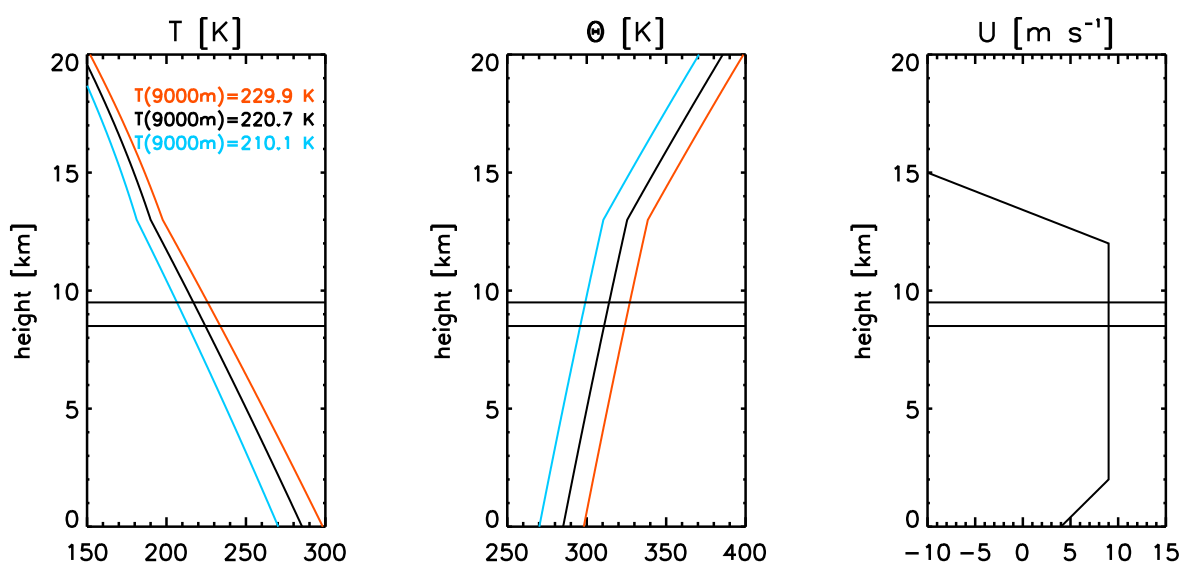

Fig. 4. Initial vertical profiles of temperature $T$, potential temperature $\theta$ and wind speed $u$ for the idealized simulations. Black lines denote the reference case. The black box shows the position of the ISSR for the reference case.
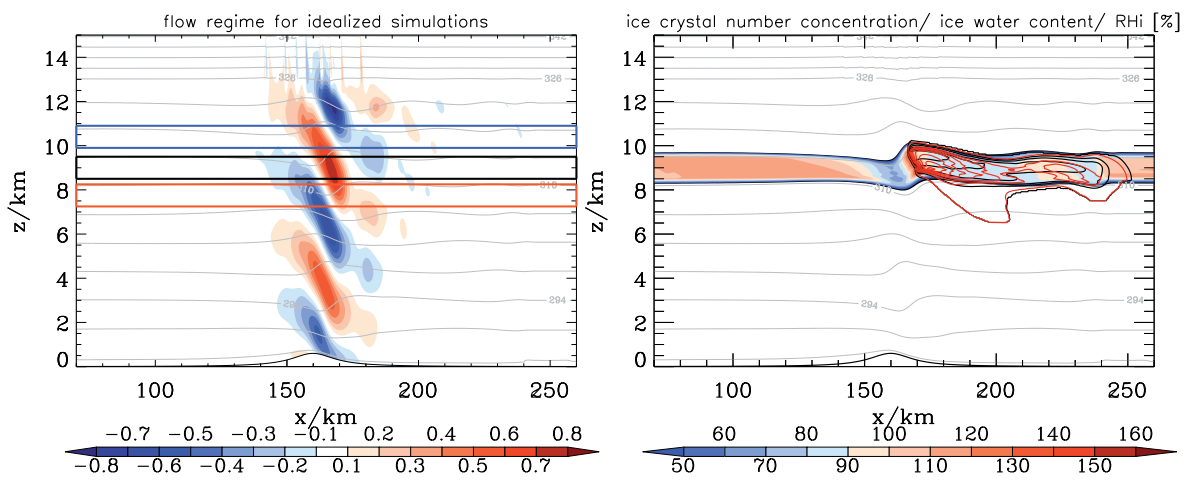

Fig. 5. Flow regime after $5 \mathrm{~h}$ used for the idealized simulations (left). Grey lines indicate lines of constant potential temperature with an increment of $4 \mathrm{~K}$. Black, blue and orange rectangles show the three different positions of the ISSR. Colors indicate the vertical velocities (left) and the relative humidity (right). Black contours show the ICNC with the lines for $0.00001,1,10,100,500,10001^{-1}$ and red contours the IWC with lines for $0.0001,1,3,6,9,12,15,18 \mathrm{mg} \mathrm{m}^{-3}$.

Figure 4 shows the initial $T(z), \theta(z)$ and $u(z)$ profiles for the reference case (black line) and the two shifted $\theta$-profiles.

In order to obtain the same flow regime for all cases, the $\theta$-profile has been shifted by adding a constant. Thus, the Brunt-Väisäla-frequency is the same in all simulations. The developing flow regime and the position of the different ISSR is shown in figure 5 (left panel).

The results shown here are after $t=5 \mathrm{~h}$. A nearly hydrostatic wave develops, which propagates vertically through the whole troposphere and is absorbed at the tropopause in a critical layer. The highest vertical velocity occurs at $\sim 9 \mathrm{~km}$ height and amounts to $\sim 0.8 \mathrm{~m} \mathrm{~s}^{-}$.

\subsection{Results}

\subsubsection{Description of the reference case}

In order to compare the effect of changed initial conditions, first the reference case is described in more detail. After a while, a hydrostatic wave forms and after $t=3 \mathrm{~h}$ the critical supersaturation for homogeneous freezing is reached, the formation of ice starts and an orographic cirrus cloud develops. Figure 5 (right panel) shows the ice crystal number concentration (ICNC) and the ice water content (IWC) after $t=5 \mathrm{~h}$, when the flow regime is in a quasi steady state.

The maximum ICNC and IWP amounts to $1.3 \mathrm{~cm}^{-3}$ and $18.9 \mathrm{mg} \mathrm{m}^{-3}$, respectively. The homogeneous freezing occurs in the updraft region of the gravity wave, whereas the maximum vertical velocity in the supersaturated layer amounts to $0.8 \mathrm{~m} \mathrm{~s}^{-1}$. The crystals are 

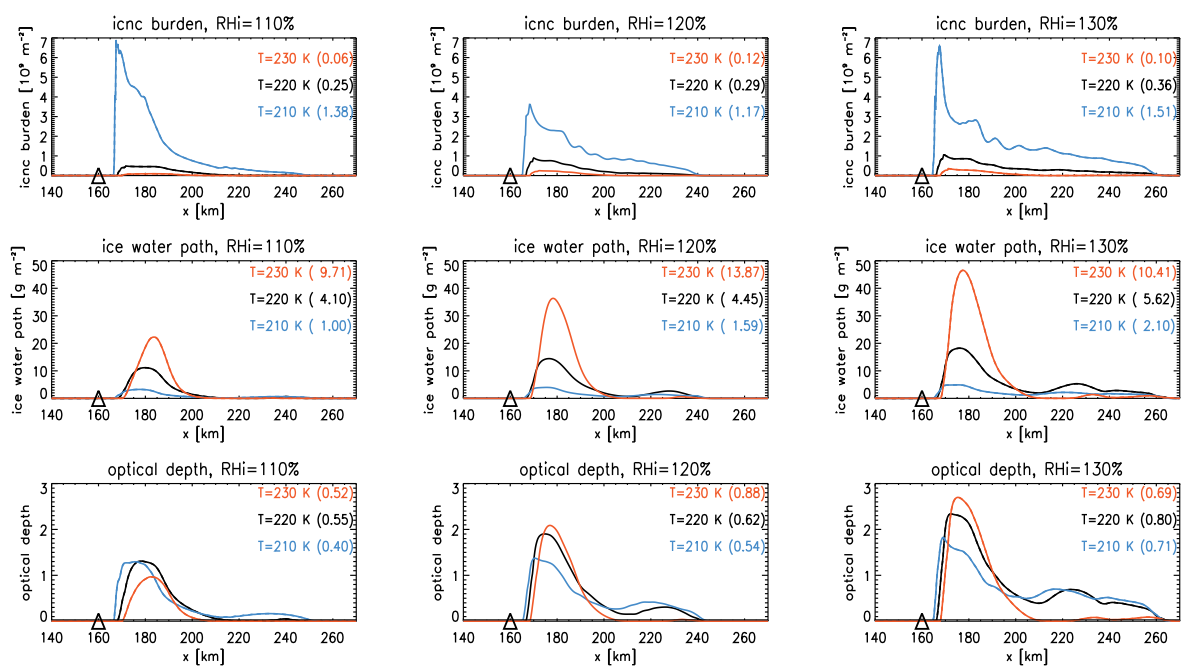

Fig. 6. Optical depth, ICNC and IWP after $t=5 \mathrm{~h}$ for (left) RHi $=110 \%$, (middle) RHi $=120 \%$ and (right) RHi $=130 \%$. Different colors indicate different temperatures inside the ISSR. Values in brackets denote the mean values, whereas here all values corresponding to $\tau>0.03$ are considered.

advected approximately $80 \mathrm{~km}$ downstream. If they become big enough they start to sediment. At $x \sim 220 \mathrm{~km}$ there is a second small updraft region as the flow regime is not perfectly hydrostatic. However the increase in RHi is not high enough to initiate a new freezing event, but the crystals are growing in this region and therefore become large enough to sediment out of the supersaturated layer. In order to investigate the changes in the microphysical properties and the optical depth and to compare it to the other simulations we calculate the vertically integrated ice water content (ice water path, IWP), ice crystal number concentration (ICNC) and cloud optical depth $(\tau)$.

For the calculation of $\tau$ the effective radius of the crystals is needed. It is calculated using the assumption of randomly orientated hexagonal cylinders and is based on the following equation (Ebert and Curry, 1992):

$r_{\mathrm{eff}}=\frac{\int_{0}^{\infty}\left(\frac{A}{4 \pi}\right)^{3 / 2} \cdot f(L) d L}{\int_{0}^{\infty} \frac{A}{4 \pi} \cdot f(L) d L}$

where $A$ denotes the total surface of a hexagonal cylinder and $f(L)$ denotes the log-normally distributed ice crystal size. Here, the integral is approximated using only the (analytical) formula for the moments of the ice crystal size distribution. For a more detailed description see Fusina et al. (2007). The cloud optical depth for the wavelength $0.2-4 \mu \mathrm{m}$ is then calculated as (Fu and Liou, 1992);

$\tau=I W P \cdot\left(a+\frac{b}{r_{\mathrm{eff}}}\right)$

where IWP is the ice water path in $\mathrm{g} \mathrm{m}^{-2}, r_{\text {eff }}$ is the effective radius in $\mu \mathrm{m}, a=-6.656 \times 10^{-3}$ and $b=3.686$.
Figure 6 (middle panel, black line) shows the results for the IWP, ICNC and $\tau$ for the reference case. The triangle denotes the position of the top of the mountain. In the strong updraft region the supersaturation passes over the critical threshold for homogeneous nucleation and ice crystals start to form and grow. The mean IWP amounts to $4.45 \mathrm{~g} \mathrm{~m}^{-2}$ an the mean ICNC is $0.29 \times 10^{9} \mathrm{~m}^{-2}$. The mean is calculated over all values where the optical depth exceeds 0.03 , which distinguishes visible from subvisible cirrus. In the second small updraft region at $x \sim 220 \mathrm{~km}$ the crystals start to grow again, but no new crystals are formed. This leads to an increased IWP and $\tau$ in this region. The mean $\tau$ is 0.62 . As the crystals are advected and even start to grow in the second updraft region the cloud has a horizontal extent of approx. $80 \mathrm{~km}$.

\subsubsection{Shift of temperature profile}

In order to investigate the formation of orographic cirrus depending on a change in temperature inside the ISSR at constant RHi, simulations with the initial $\theta$-profiles shown in Fig. 4 are carried out. The assumptions of a constant relative humidity and warmer temperatures represent the conditions in a future climate. The results are also shown in Fig. 6 (blue and red lines). The results shown here are for $t=5 \mathrm{~h}$, although in the simulation with $\mathrm{RHi}=110 \%$ the formation of the cirrus cloud starts $\sim 1 \mathrm{~h}$ later than in the other simulations. This means, that the figure for $\mathrm{RHi}=110 \%, 120 \%$ and $\mathrm{RHi}=130 \%$ are not directly comparable as the pictures refer to different stages of development of the cloud. Comparing the results for all cases at the same time $(3 \mathrm{~h})$ after the first nucleation does not change the overall picture. Therefore here 
the results after $t=5 \mathrm{~h}$ are shown referring to different stages of development of the cloud.

For the case of $\mathrm{RHi}=120 \%$ (middle panel) it can be seen that the IWP decreases strongly with decreasing temperature when RHi is kept constant because much less water vapor is available at colder temperatures. IWP for the cold case decreases to $1.6 \mathrm{~g} \mathrm{~m}^{-2}$, which corresponds to a reduction of $64 \%$. The mean value for the warm case amounts to $13.9 \mathrm{~g} \mathrm{~m}^{-2}$, which corresponds to an increase of $212 \%$ compared to the reference case. The ICNC increases strongly for the cold case and decreases for the warm case as the crystal growth rate decreases significantly with decreasing temperature and thus the water vapor is removed at a slower rate and RHi remains high enough for further homogeneous nucleation (see Kärcher and Lohmann (2002); Spichtinger and Gierens (2009)). The mean ICNC for the warm case is $0.12 \times 10^{9} \mathrm{~m}^{-2}$ which represents a reduction of $59 \%$, whereas for the cold case there is an increase of $303 \%$ to $1.17 \times 10^{9} \mathrm{~m}^{-2}$. In the warm case there is no second maximum in the IWP. Due to the warmer temperatures there are less crystals which grow more rapidly and start to sediment. Therefore the horizontal extent of the cloud is reduced compared to the reference case but the mean optical depth is higher. In the cold case the crystals are advected over about $80 \mathrm{~km}$ without a drastic fallout and start to grow in the second small updraft region. The resulting optical depth for $T=230 \mathrm{~K}$ amounts to 0.88 and for $T=210 \mathrm{~K}$ to 0.54 . This corresponds to a decrease/increase of $13 \% / 42 \%$ for the cold and warm case, respectively. Thus, in the warm case the increase of IWP dominates the decrease in ICNC and the mean $\tau$ is highest although the cloud is not as large in its horizontal extent. For the cold case the decrease in IWP dominates the strong increase in ICNC and the optical depth decreases compared to the reference case. Thus temperature changes inside the ISSR change the optical depth of the cloud by changing the IWP and ICNC. This example points out that changes in IWP strongly dominate the behavior of $\tau$ and cannot be compensated by changes in ICNC. Only for the highest temperature $(T=230 \mathrm{~K})$, sedimentation becomes important. The increased sedimentation leads to a reduction of the horizontal extent of the cloud and the IWP and could therefore also lead to a decrease of $\tau$.

When the initial supersaturation is increased to $130 \%$, more water vapor is available and the IWP is higher than in the reference case. In the warmest case $(T=230 \mathrm{~K})$ the crystals start to sediment. However, there still remain some ice crystals in this case (Rhi $=130 \%, T=230 \mathrm{~K}$ ) and the mean $\tau$ decreases compared to the case where $T=220 \mathrm{~K}$ and is even lower than for the cold case. This is caused by the fact that $\tau$ is still higher than 0.03 and is therefore taken into account for the calculation of the mean value of $\tau$. In contrast, in the case where Rhi $=120 \%$ the crystals sediment completely leading to a higher mean value of $\tau$ but a smaller horizontal extent. Thus if the increase in temperature is strong enough and the initial ice supersaturation is high, the increase in $\tau$ due to more IWP is not necessarily the dominant effect anymore as the cloud ice is reduced due to sedimentation and the optical depth is reduced. As a temperature increase of $10 \mathrm{~K}$ inside the ISSR may not be realistic for a future climate, we can conclude that the increase in IWP at warmer temperatures and constant relative humidity and the resulting increase in optical depth is the dominant process. However, it has to be considered that the opposing effect of a reduced optical depth due to sedimentation is also possible. If the supersaturation is reduced to $110 \%$, a slightly different picture shows up. As the initial RHi is relatively low, the difference in IWP between the different temperatures is not as much pronounced as for high RHi. Therefore the reduction in ICNC due to warmer temperatures is not completely compensated by the increase in IWP and the resulting $\tau$ for the warm case is slightly lower than for $T=220 \mathrm{~K}$ but still higher than for the cold case.

\subsubsection{Change of height of the ISSR}

In a changing climate an increase in moisture is expected. This increase influences the propagation of gravity waves in the atmosphere and leads to an increase of the vertical wavelength of the waves, which means that the ISSR shifts to a different position in the wave. Therefore, we investigated the changes of the formation of orographic cirrus due to a change of the height of the ISSR which corresponds to a different position in the wave phase compared to the reference case. The different heights of the ISSR can be seen in fig.5. The height of the ISSR is chosen in a way that the temperatures inside the low/high ISSR amount to $230 / 210 \mathrm{~K}$ for a better comparison to the other cases discussed in Sect. 4.1.2. In the case of the high and low ISSR the maximum vertical velocities are lower than in the reference case and decrease from $0.8 \mathrm{~m} \mathrm{~s}^{-1}$ to $0.6 \mathrm{~m} \mathrm{~s}^{-1}$. Furthermore, for the low case, the air first has to pass a region of strong downdraft before it reaches the updraft region where a cloud can form. Figure 7 shows the results for the three different heights of the ISSR.

The left panel shows the results when the ISSR is shifted to a higher/lower position so that the temperature inside the lower/higher ISSR amounts to $210 \mathrm{~K} / 230 \mathrm{~K}$, respectively. The initial supersaturation is $120 \%$. Due to the decrease in temperature at constant RHi the IWP decreases strongly for the high ISSR. However, no cloud forms when the ISSR is at its low position. Although the vertical velocity in the high and low case are nearly the same, the net lifting of the air in the low case is much less. Therefore the critical supersaturation for the homogeneous freezing is not reached and no cloud forms. For the high case the initiation of the freezing event is shifted $\sim 10 \mathrm{~km}$ upstream due to the backward shift of the waves crest with height. The ICNC shows a strong increase for the high case as the temperature inside the ISSR is $T=210 \mathrm{~K}$. We again observe that the decrease in IWP due to the colder temperature is the dominant effect and the resulting optical depth is decreased. The middle panel shows the 

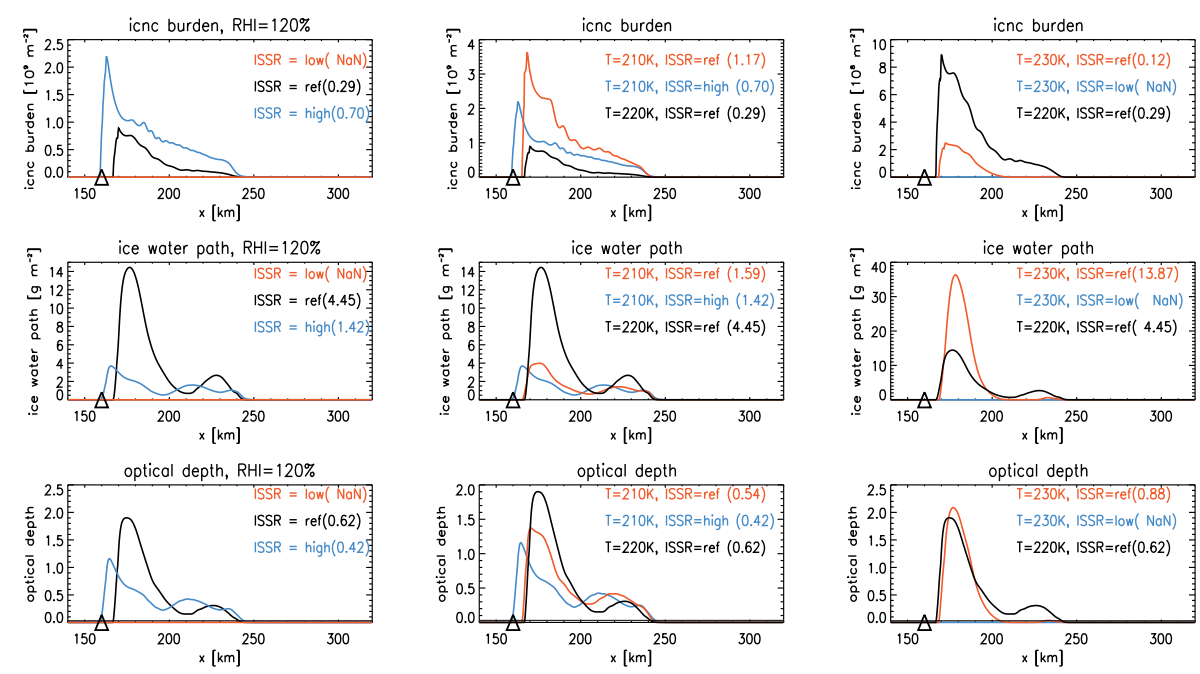

Fig. 7. Optical depth, ICNC and IWP after $t=5 \mathrm{~h}$ for (left) RHi $=120 \%$ and three different positions of ISSR, (middle) comparison of a decrease in temperature due to a change of the height of the ISSR (blue line) and shift of the initial temperature profile (red line) to $T=210 \mathrm{~K}$ at $\mathrm{RHi}=120 \%$ and (right) same as in the middle panel but for a temperature increase to $T=230 \mathrm{~K}$ at $\mathrm{RHi}=120 \%$. Note that the vertical axis differs in each column.

results for the simulations where the temperature inside the ISSR has been changed to $T=210 \mathrm{~K}$ once due to a change in the initial temperature profiles (red lines) and once due to the shift of the ISSR to a higher position (blue lines). Thus a comparison of the changes due to a temperature change only and due to a combined change of temperature and vertical velocity is possible. In both cases the IWP decreases strongly due to the lower temperature, but for $T=210 \mathrm{~K}$ the IWP is nearly the same, as the IWP is mainly determined by the RHi, but the position of the cloud is shifted upstream for the high position of the ISSR. For the increase of ICNC a difference between both simulations can be seen. Here, the change in the dynamics as well as the change in temperature affects the ice crystal formation. The decrease in temperature leads to an increase in ICNC in both cases. This increases is more pronounced in the case where the initial temperature profile is shifted as then the ISSR remains in the region with the highest vertical velocities. When the ISSR is shifted to a higher position, the maximum vertical velocity decreases and hence the ICNC. The resulting optical depth is therefore lowered even more for the high ISSR as the dynamical changes suppress the strong increase in ICNC. The right panel shows the same as the middle panel but for an increase in temperature due to a lowering of the ISSRs position and a shift in the initial temperature profile. It can be seen that in this case the shift of the initial temperature profile leads to an enhanced IWP and optical depth, whereas in the case of the low ISSR the change in the dynamics completely suppresses the formation of a cloud. When the initial supersaturation is enhanced to $\mathrm{RHi}=130 \%$, a cloud forms even in the low ISSR (not shown here). However, the resulting IWP is lower com- pared to the case where the ISSR is in the reference height although the temperature is much higher and much more water vapor is available. Therefore a strong reduction of the $\tau$ can also be seen here as the dynamical changes dominate the increase in temperature.

We did the same simulations for a non-linear flow regime by increasing the mountain height $h_{0}$ to $850 \mathrm{~m}$ which leads to $\hat{h}=0.94$. For this regime we found the same features for the development of the orographic cirrus clouds as in the linear flow regime (not shown).

\section{Simulations with IPCC initial profiles}

In order to investigate the formation of orographic cirrus clouds in a changing climate, simulations with initial profiles for the equivalent potential temperature, wind speed, pressure and specific humidity from the IPCC fourth assessment report have been carried out (Meehl et al., 2007). We used the results from the ECHAM simulation obtained for the A1B emission scenario and investigated the effect of a warmer climate on the formation of orographic cirrus in a linear and non-linear flow regime for two regions representative for the Northern and Southern Hemisphere. All simulations have been performed for the particular winter and summer months.

\subsection{Model setup}

For simulating orographic cirrus clouds we use a 2-D domain (x-z-plane) with a horizontal extension of $320 \mathrm{~km}$ and a vertical extension of $20 \mathrm{~km}$ with a bell shaped mountain in 

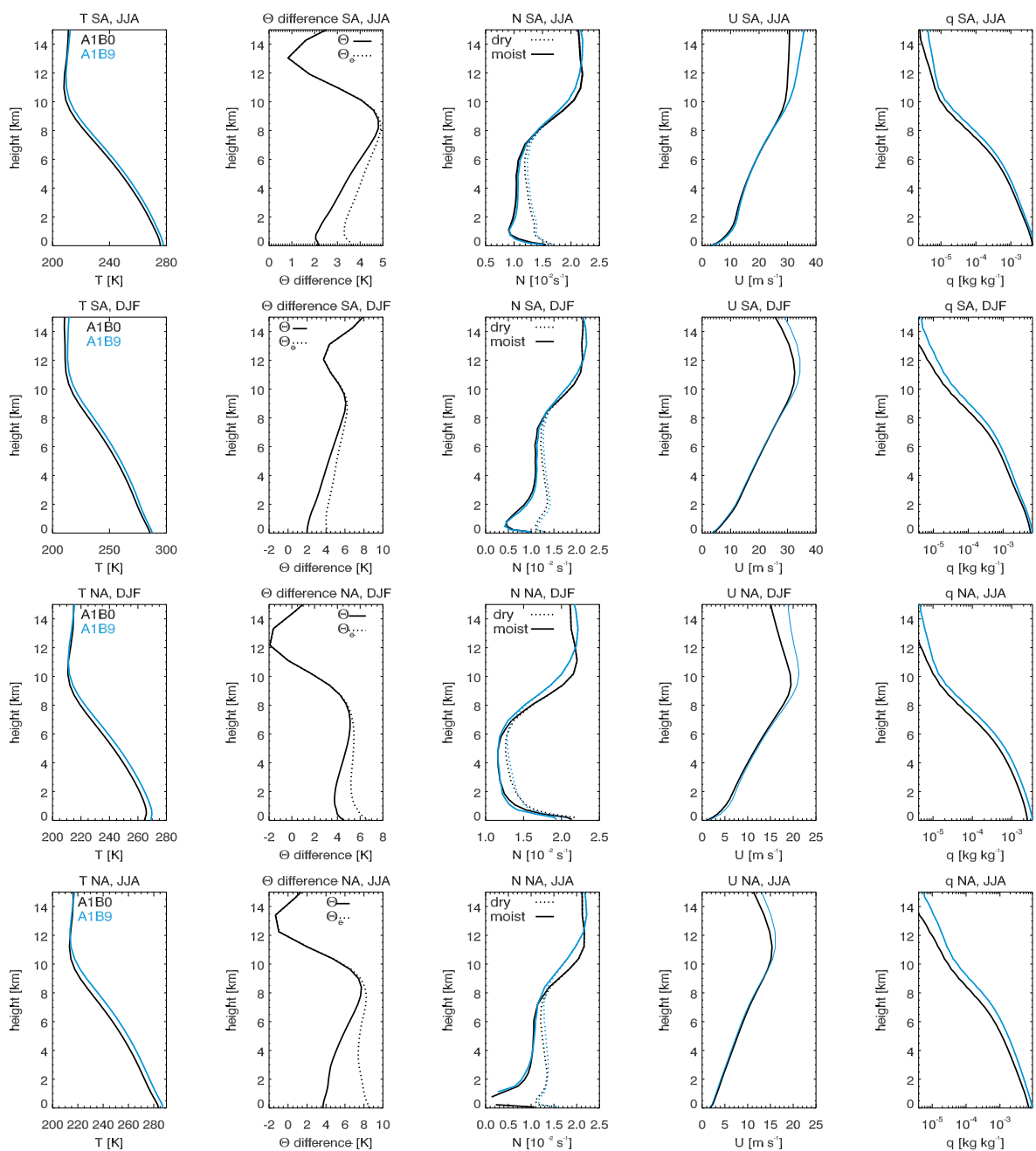

Fig. 8. Ten year mean of the initial profiles of temperature $T$, difference of potential temperature $\theta$ and equivalent potential temperature $\theta_{e}$ between A1B9 and A1B0, moist and dry Brunt-Väisäla frequency $N$, wind speed $u$ and specific humidity $q$ for A1B0 (black) and A1B9 (blue) for the Southern Hemisphere winter and summer month (upper two panels) and Northern Hemisphere winter and summer months (lower two panels).

the middle of the domain. Two different flow regimes have been investigated. The change from the linear to the nonlinear flow regime was performed by increasing the mountain height from $600 \mathrm{~m}$ in the linear to $1850 \mathrm{~m}$ in the non-linear case. The horizontal and vertical resolutions are $d x=250 \mathrm{~m}$ and $d z=50 \mathrm{~m}$ for the linear flow regime and $d x=1000 \mathrm{~m}$ for the non-linear regime. The simulations for the linear flow regime have been carried out for 6 hours. For the non-linear case the simulations are extended to $10 \mathrm{~h}$ because it takes much longer until a stable flow is reached.

The model is initialized with the ambient (equivalent) potential temperature, pressure and wind profiles $\theta_{e}(z), p(z)$ and $u(z)$ taken from the IPCC simulations. Two regions representative for the Northern and Southern Hemisphere have been selected in order to investigate the effect of a warm- ing climate. In the Southern Hemisphere mean profiles averaged over a region from $60^{\circ} \mathrm{W}$ to $80^{\circ} \mathrm{W}$ and from $40^{\circ} \mathrm{S}$ to $55^{\circ} \mathrm{S}$ representative for the tip of South America have been taken. For North America a region from $115^{\circ} \mathrm{W}-130^{\circ} \mathrm{W}$ and $45^{\circ} \mathrm{N}-60^{\circ} \mathrm{N}$ has been selected. For both cases the profiles for the particular winter and summer month (December, January, February and June, July, August) are taken. Additionally, only values over land are used for the calculation of the mean vertical profiles. In order to represent the conditions of the beginning and the end of the 21 century, a ten year mean for the years 2001-2010 (A1B0) and 2090-2099 (A1B9) has been calculated. Figure 8 shows the initial profiles for the Southern and Northern Hemisphere for the winter and summer months. 

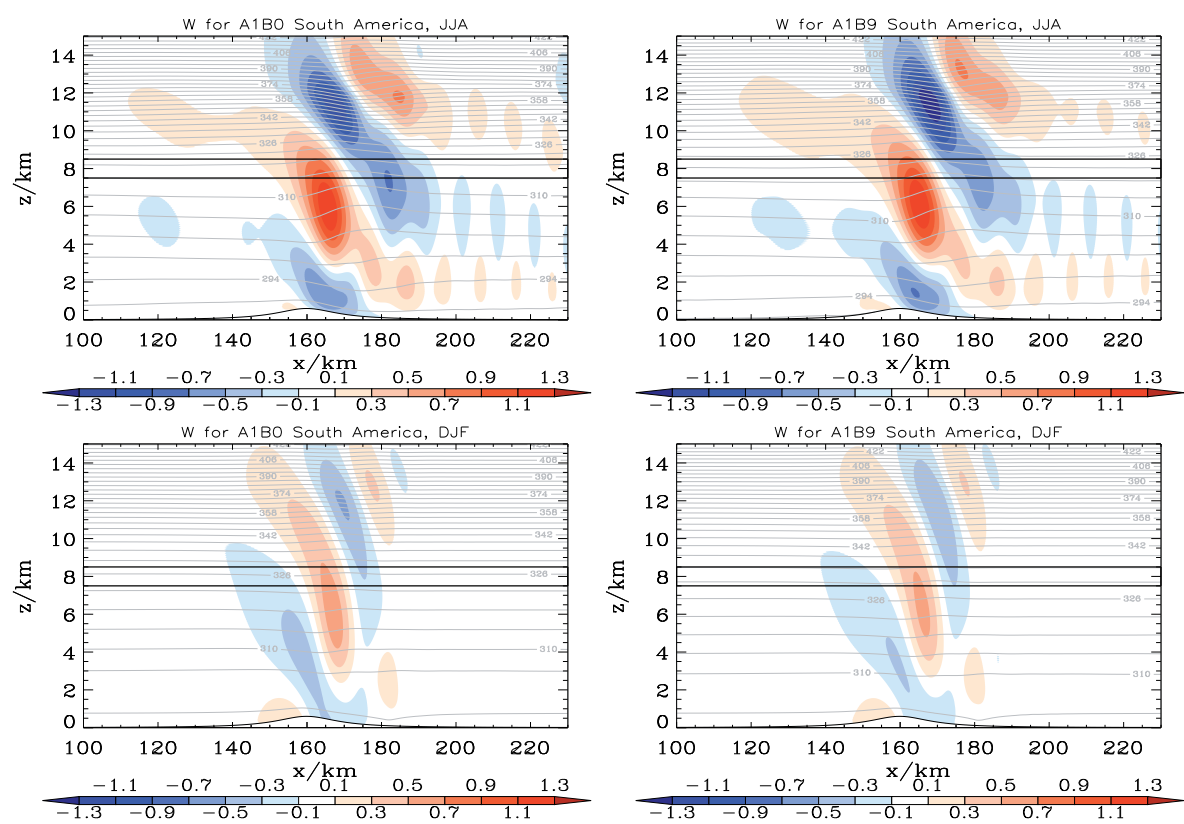

Fig. 9. Flow regime for South America after $t=5 \mathrm{~h}$ for the initial profiles of A1B0 (left) and A1B9 (right) and for winter (JJA, upper panels) and summer (DJF, lower panels). Grey lines denote the lines of constant potential temperature, colors indicate the vertical velocity. The black box shows the initial position of the supersaturated layer.

In order to account for the influence of moisture on the static stability and hence the propagation of gravity waves, the simulations are performed with the equivalent potential temperature $\theta_{e}$ instead of the potential temperature $\theta$. The equivalent potential temperature is calculated as

$\theta_{e}=\theta \cdot \exp \left(\frac{L_{v} q}{c_{p} T}\right) \approx\left(T+\frac{L_{v}}{c_{p}} q\right)\left(\frac{p_{0}}{p}\right)^{\frac{R_{d}}{c_{p}}}$

where $T$ is the temperature of air, $p$ is the pressure, $p_{0}$ is a reference pressure, $R_{d}=287 \mathrm{~J} \mathrm{~kg}^{-1} \mathrm{~K}^{-1}$ is the specific gas constant of air, $c_{p}=1004 \mathrm{~J} \mathrm{~kg}^{-1} \mathrm{~K}^{-1}$ is the specific heat of dry air at constant pressure, $L_{v}$ is the latent heat of evaporation which has been set to $2500 \mathrm{~kJ} \mathrm{~kg}^{-1}$ and $q$ is the water vapor mixing ratio. Taking $\theta_{e}$ implies that condensation occurs everywhere, which is usually not realistic. Therefore additional "dry" simulations with the potential temperature $\theta$ instead of $\theta_{e}$ as initial profiles are performed. These simulations then cover two extreme cases where condensation in lower levels is neglected completely or is assumed to occur everywhere. In the following the moist simulations are explained in detail whereas the results of the corresponding dry simulations are only described briefly. The results of all simulations are also summarized in Tables 1 and 2. In order to simulate the formation of orographic cirrus a supersaturated layer is implemented. The initial supersaturation is $\mathrm{RHi}=130 \%$. For every hemisphere simulations with the initial profiles of $\theta_{e}(z), u(z)$ for the beginning (A1B0) and the end of the century (A1B9) have been carried out. Fur- thermore, we assume that the relative humidity with respect to water stays constant in a changing climate. This assumption is based on model simulations that produce increases in water vapour concentrations which are similar to those which are predicted if a constant relative humidity is assumed (Held and Soden, 2000). The assumption of a constant relative humidity with respect to water leads to a decrease in relative humidity with respect to ice. However, for the temperature increase we consider here, this decrease is very small. Therefore we also assume the relative humidity with respect to ice to stay constant.

\subsection{South America: linear flow regime}

Figure 9 shows the resulting flow regime for the moist simulations initialized with the IPCC profiles for South America after $t=5 \mathrm{~h}$ with the initial profiles for 2001-2010 and 20902099.

In all cases a gravity wave develops which propagates through the whole troposphere. In winter time, the atmosphere is much more stably stratified than in summer and the vertical velocities occuring in the wave lie between $-1.5 \mathrm{~m} \mathrm{~s}^{-1}$ and $1.3 \mathrm{~m} \mathrm{~s}^{-1}$. The simulation A1B9 shows higher velocities, however, the vertical velocities inside the supersaturated layer are only slightly higher in the simulation A1B9. The increase in wind speed in a future climate as well as the increase in moisture have an influence on the flow regime. The increase in moisture in a future climate influences the stability of the atmosphere. It leads to a less stable 

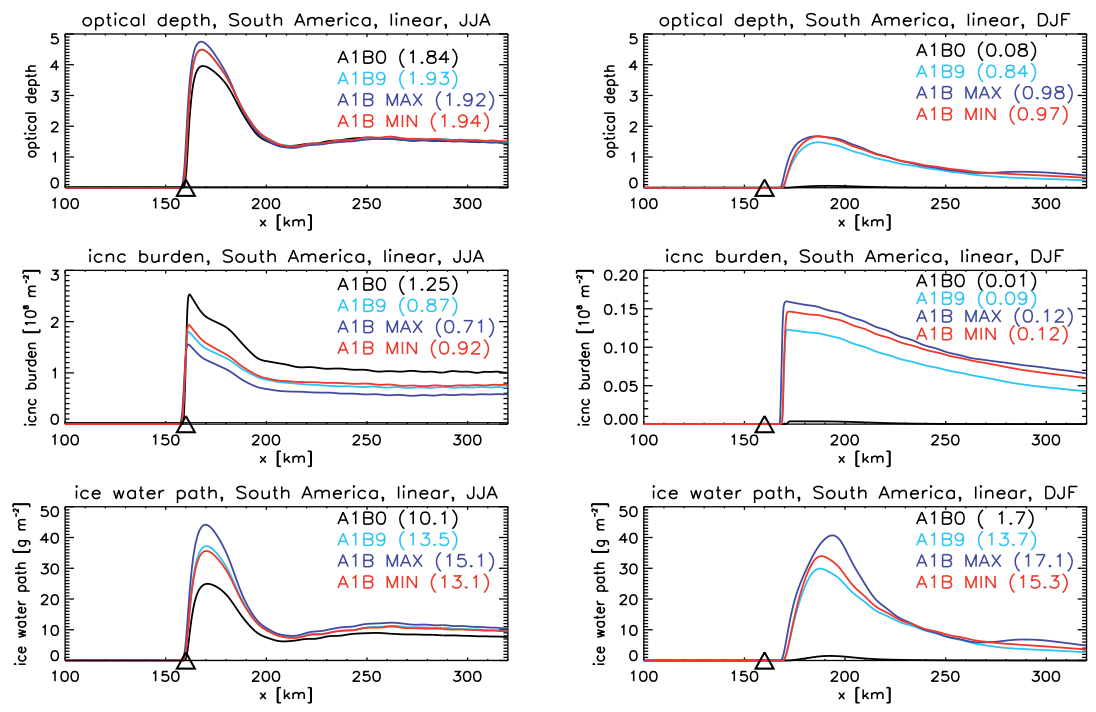

Fig. 10. Optical depth, ICNC and IWP for the Southern Hemisphere for winter (left) and summer (right). Black lines show the results for the initial profiles for A1B0, blue lines show the results obtained with the initial profiles from the ECHAM A1B simulation averaged over 2090-2099 (A1B9), dark blue lines show the results for the $\mathrm{A}_{1} \mathrm{~B}_{\max }$ simulation and red lines for the $\mathrm{A}_{1} \mathrm{~B}_{\min }$ simulation.

profile and thus to smaller amplitudes and vertical velocities (Jiang, 2003; Durran and Klemp, 1983). However, as can be seen in Fig. 8 (upper panels) the moist Brunt-Väisäla frequency nearly stays the same and the influence of a change in moisture is very weak. The increase in horizontal wind speed leads to an increase of the amplitudes. In the resulting flow the effects of increased moisture and horizontal wind speed nearly compensate each other and the amplitudes and vertical velocities remain nearly the same for both simulations. As the vertical wavelengths also depends on the stability and hence the moisture, a weak increase in the vertical wavelength can be seen for the run A1B9. The ISSR therefore occurs in a slightly different phase of the wave.

During the summer months the atmosphere is less stable and the developing gravity wave is weaker than in the winter case. The maximum/minimum vertical velocities therefore only reach $+0.6 \mathrm{~m} \mathrm{~s}^{-1}$ and $-0.5 \mathrm{~m} \mathrm{~s}^{-1}$ in the A1B0 and A1B9 scenario. However, the gravity wave for A1B9 is slightly weaker then for A1B0 as the vertical profile for A1B9 is less stable in the lowest levels and the horizontal wind speed is smaller (see Fig. 8, second row).

In order to investigate the changes in cirrus cloud properties in a changing climate, again the vertically integrated ice crystal number concentration (ICNC), the ice water path (IWP) and the optical depth are calculated. Figure 10 shows the results for the two simulations after $5 \mathrm{~h}$ for summer and winter.

An orographic cirrus cloud develops above the mountain top in both seasons. As the downdrafts of the gravity waves are not very strong, the crystals survive this downdraft and are advected more than $150 \mathrm{~km}$ downstream. There are several effects influencing the optical depth of the developing cirrus cloud. First of all, the assumption of a constant relative humidity in a changing climate with higher temperatures leads to a strong increase in IWP. In the winter case (left panel), the mean IWP averaged over the whole cloud increases from $10.1 \mathrm{~g} \mathrm{~m}^{-2}$ in the A1B0 simulation to $13.4 \mathrm{~g} \mathrm{~m}^{-2}$. ICNC is influenced by the vertical velocities and the temperature in their formation region. As in the winter case the vertical velocity is nearly the same in the ISSR for both simulations, the strong reduction of ICNC in the A1B9 simulation is caused by the much warmer temperatures in the A1B9 case. The temperature in the middle of the ISSR in $8000 \mathrm{~m}$ height increases from $T=223.6 \mathrm{~K}$ for the A1B0 simulation to $T=227.1 \mathrm{~K}$ for the A1B9 case. This strong increase speeds up the growth rates of the ice crystals. Therefore the supersaturation is depleted faster and no new crystals can be formed. Additionally they grow large enough to sediment out and thus represent a sink for the water vapor. However in this case no reduction of the horizontal extent of the cloud can be seen as the differences in temperatures are much weaker here than in the idealized simulations. The resulting optical depth shows an increase for the A1B9 case. Thus, the increase in IWP dominates over the reduction of the ICNC and the resulting cloud is optically thicker in the A1B9 case. This behavior shows that the thermodynamical changes are more important than the dynamical changes for this particular case.

In order to estimate the effect of the uncertainty in the predicted warming on the formation of orographic cirrus and to evaluate if changes due to the uncertainty in the predicted warming are bigger than the changes from current to future 

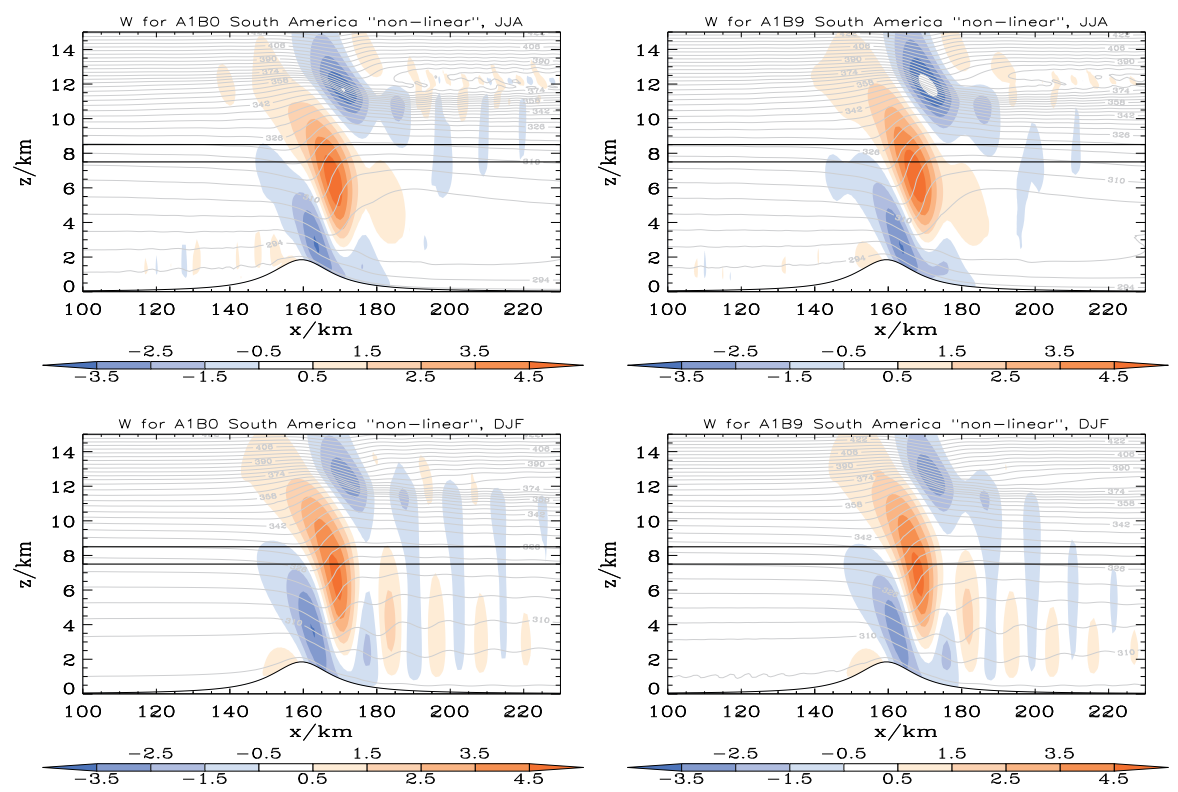

Fig. 11. Flow regime for South America after $t=10 \mathrm{~h}$ for the initial profiles of A1B0 (right) and A1B9 (left) for winter (JJA, upper panels) and summer (DJF, lower panels). Grey lines denote the lines of potential temperature, colors indicate the vertical velocity. The black box shows the initial position of the supersaturated layer.

climate, additional simulations have been performed. From the regional climate projections from the IPCC (Christensen et al., 2007) the minimum and maximum warming for the region of South America for summer (DJF) and winter (JJA) has been taken. For winter (JJA) the predicted increase in surface temperature over land varies between $1.7 \mathrm{~K}$ and $3.6 \mathrm{~K}$. The initial profile used in the simulation before is based on the ECHAM A1B simulation and shows an increase in surface temperature of $2.1 \mathrm{~K}$ for the Southern Hemisphere. Therefore two additional simulation have been performed where we added/subtracted $+1.5 /-0.4 \mathrm{~K}$ to the temperature profile $T(z)_{\mathrm{A} 1 \mathrm{~B} 9}$ in order to obtain the extreme values of the predicted temperature change. For simplicity it is assumed that the stability remains the same as in A1B9 but only the temperature changes. This assumption is justified as the dynamical changes are negligible here. Figure 10 (left panels) shows the results for the minimum and maximum predicted temperature change for the winter months.

A strong increase in IWP from the beginning to the end of the century for all simulations can be seen as the temperature increases. This also leads to a strong reduction of the ICNC for all simulations whereas the decreases are most pronounced for the $\mathrm{A}_{1} \mathrm{~B}_{\max }$ simulation where the highest temperatures are reached. The resulting optical depth is much higher for all simulations at the end of the century. However, the mean optical depth is largest for the $\mathrm{A}_{1} \mathrm{~B}_{\text {min }}$ simulation. This is caused by a strong increase in IWP but a small decrease in ICNC.
In the summer case a slightly different picture emerges. The IWP increases as again more water vapor is available. However, ICNC also increases very strongly although the temperature is much warmer in the A1B9 case. This can be explained here as follows: The critical supersaturation for the initiation of the homogeneous freezing process decreases with increasing temperature. Therefore, in the upper part of the ISSR the critical supersaturation is only exceeded in the warmer A1B9 case and crystals start to form. In the colder A1B0 case where the critical supersaturation is higher, the relative humidity with respect to ice stays below the critical value and no crystals can form. This increase in IWP combined with an increase in ICNC leads to a strong increase in optical depth from 0.08 to 0.87 in the A1B9 case. This effect might be strongly influenced by the use of mean profiles. If the variability of the meteorological conditions would have been taken into account, plenty of cases would arise where the nucleation threshold would be exceeded. Thus, this results might overestimate the effect of climate change. Compared to the winter months, the optical depth is lower in summer. The IWP is similar for both cases as it is mainly determined by the initial supersaturation. However, the ICNC is an order of magnitude lower than winter. This is caused by much lower vertical velocities combined with higher temperatures during the summer months.

For the summer months we also investigated the effects of the uncertainty in the predicted warming on the properties of orographic cirrus. Here, the predicted warming lies between $1.5 \mathrm{~K}$ and $4.3 \mathrm{~K}$. The ECHAM A1B simulation predicts a 

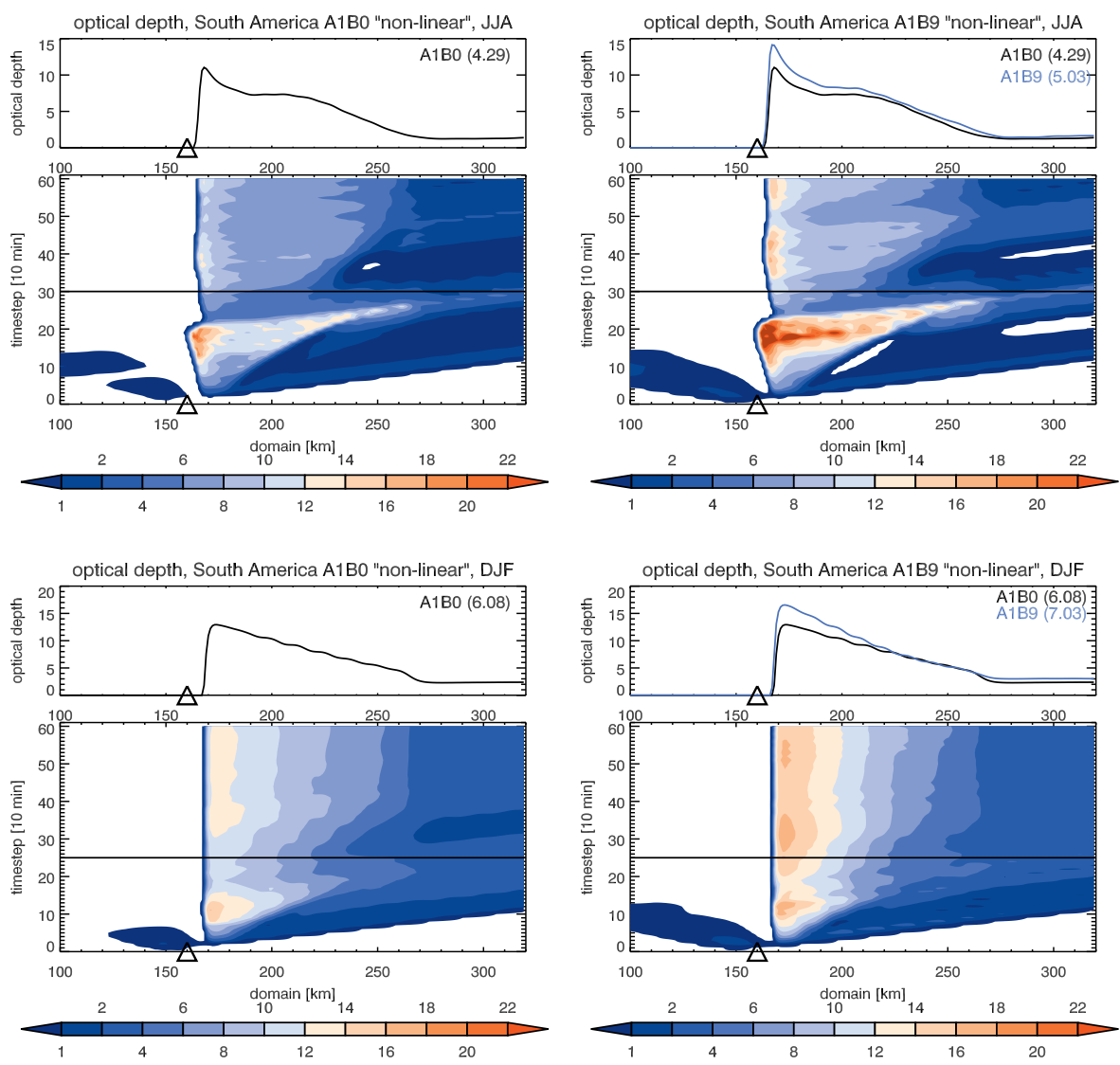

Fig. 12. Time development of the optical depth for the A1B0 (left) and A1B9 (right) simulations for winter (JJA, upper panels) and summer (DJF, lower panels). The triangle denotes the top of the mountain, and the black line shows the point in time when the flow becomes stable. The small panels show the time average from $5-10 \mathrm{~h}$ and $4-10 \mathrm{~h}$, respectively.

surface warming of $2.0 \mathrm{~K}$. Therefore we added/subtracted $+2.3 /-0.5 \mathrm{~K}$ to the original temperature profile of the summer months. Again, for all A1B9 simulations the optical depth is much higher. The highest optical depth is reached for the $\mathrm{A}_{1} \mathrm{~B}_{\max }$ case where the increase in temperature and hence IWP is strongest. As mentioned earlier, ICNC increases, as due to the warmer temperatures the critical supersaturation is exceeded. The ICNC for $\mathrm{A}_{1} \mathrm{~B}_{\text {min }}$ is higher than for A1B9 as the temperature is slightly lower which leads to more ice crystals. The highest ICNC is reached in the $\mathrm{A}_{1 \mathrm{~B}} \mathrm{max}_{\text {case }}$ where the critical value of the supersaturation is exceeded in a larger region than in the colder cases of $\mathrm{A}_{1} \mathrm{~B}_{\text {min }}$ and $\mathrm{A} 1 \mathrm{~B} 9$.

The corresponding dry simulations show a slightly different behavior (not shown here). For the winter months (JJA), the changes in the flow regimes from A1B0 to A1B9 are again very small. Higher temperatures thus lead to a strong decrease in the simulated ICNC and an increase in the IWP. However, the decrease in ICNC is more pronounced than in the moist simulation and cannot be compensated by the increased IWP. The resulting optical depth therefore decreases $\sim 8 \%$ from $\mathrm{A} 1 \mathrm{~B} 0$ to $\mathrm{A} 1 \mathrm{~B} 9$. In the summer months (DJF), the vertical velocity decreases from A1B0 to A1B9. In combination with higher temperatures this leads to a strong reduction in the ICNC which cannot be compensated by the increased IWP. The optical depth is therefore lower in the A1B9 simulation. In comparison to the moist simulations, the vertical velocity is much higher in the dry case caused by a more stable stratification. In contrast to the moist simulations where the critical supersaturation is only exceeded in the A1B9 simulation and the ICNC therefore strongly increases from $\mathrm{A} 1 \mathrm{~B} 0$ to $\mathrm{A} 1 \mathrm{~B} 9$, in the dry simulation nucleation also starts in the $\mathrm{A} 1 \mathrm{~B} 0$ case as the vertical velocities are much higher such that the adiabatic cooling is strong enough to exceed $S_{c r}$.

In general, we can state that for all moist cases the increase in IWP and hence the optical depth from the current to the future climate is the dominant effect. The changes in the results due to the uncertainties in the predicted warming are much less than the changes from A1B0 to A1B9. However, the dry simulations show the opposite results with a decreased optical depth in future. 

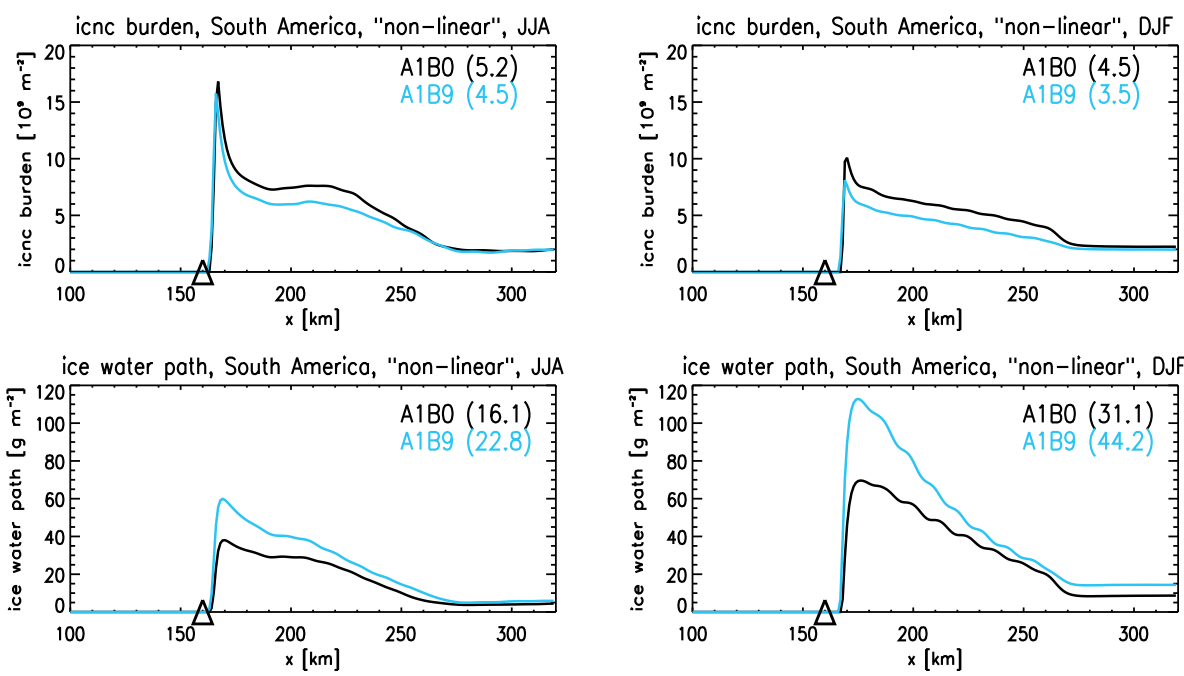

Fig. 13. ICNC and IWP for the simulations $\mathrm{A} 1 \mathrm{~B} 0$ and $\mathrm{A} 1 \mathrm{~B} 9$ averaged over $t=5-10 \mathrm{~h}$ for JJA and $t=4-10 \mathrm{~h}$ for DJF for South America. The triangle denotes the tip of the mountain.
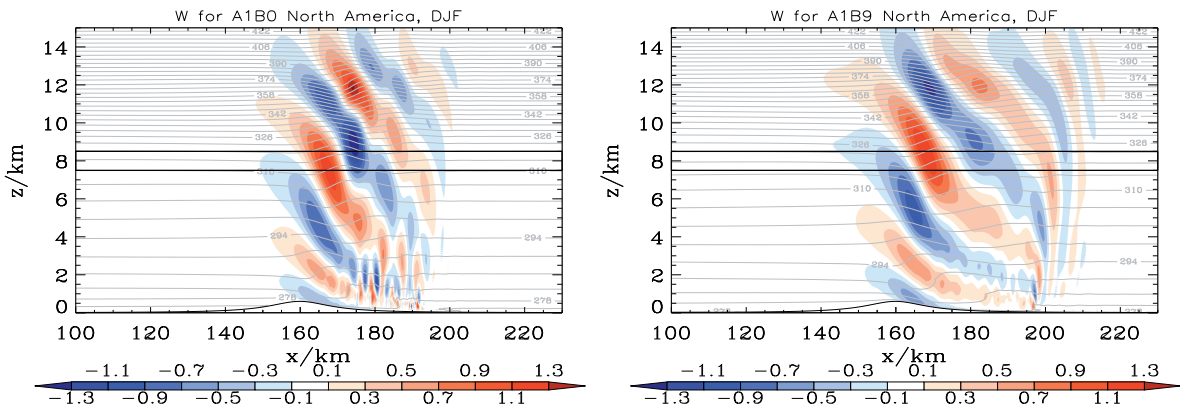

Fig. 14. Flow regime for North America after $t=5 \mathrm{~h}$ for the initial profiles of A1B0 (right) and A1B9 (left). Grey lines denote the lines of constant potential temperature, colors indicate the vertical velocity. The black box shows the initial position of the supersaturated layer.

\subsection{South America: hydraulic jump}

To investigate the effects of a warmer climate in a different flow regime, additional simulations with an increased mountain height have been performed. The increase in mountain height leads to higher Froude numbers and the flow becomes non-linear. Figure 11 shows the resulting flow regime after $t=10 \mathrm{~h}$ for the beginning and the end of this century for the winter and summer months.

Due to the changes in moisture one could expect a shift to a more linear regime as the onset of gravity wave breaking is delayed (Jiang, 2003). However, since in our case the changes in moisture are weak this effect cannot be seen here. The resulting flow regimes are very similar, only a slight increase in the vertical wavelength from A1B0 to A1B9 can be seen for the winter month which is caused by the increase in moisture. The resulting optical depth of the cirrus clouds for the four simulations is shown in Fig. 12. As the flow needs a spinup time of $\sim 5 \mathrm{~h}$ in winter and $\sim 4 \mathrm{~h}$ in summer until it becomes stable, we show the time development of the optical depth for both seasons.

We evaluate the results after $t=5 \mathrm{~h}$ for JJA and after $t=4 \mathrm{~h}$ for DJF when the flow becomes stable. As can be seen very clearly, the resulting optical depth after $t=5 \mathrm{~h}$ and $t=4 \mathrm{~h}$, respectively is higher for the A1B9 simulation. Thus, the same features as in the linear case show up. The changes in the flow regimes for the current and future climate are relatively weak, but due to the higher temperatures in a future climate we obtain less ice crystals but more ice water content and thus a higher optical depth in both seasons as shown in Fig. 13.

As in the linear flow regime the thermodynamical changes dominate the dynamical changes for this South American case. In contrast to the linear flow regime, here the optical depth is higher in summer. The changes in the flow regime between summer and winter are not as much pronounced 

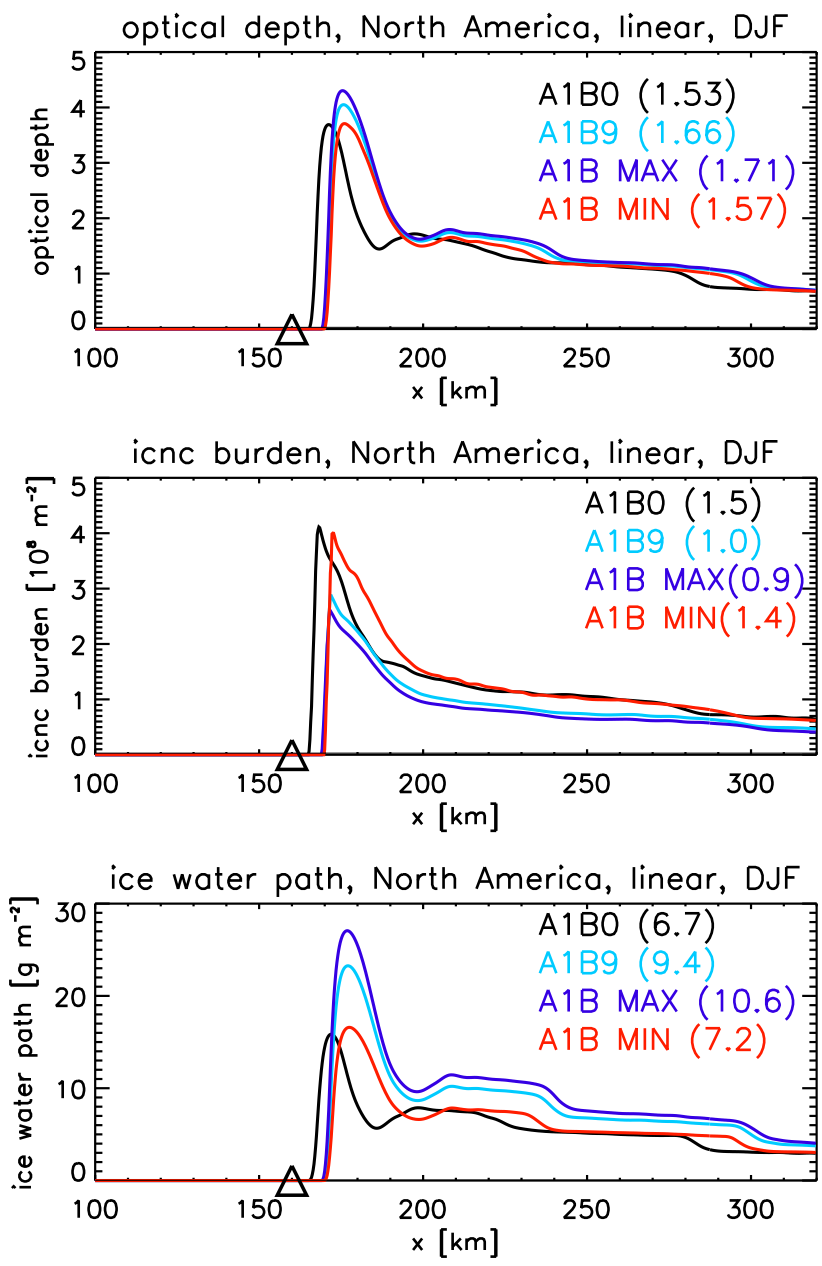

Fig. 15. Optical depth, ICNC and IWP for the Northern Hemisphere. Black lines show the results for the initial profiles for A1B0, blue lines show the results obtained with the initial profiles from the ECHAM A1B simulation averaged over 2090-2099 (A1B9), dark blue lines show the results for $\mathrm{A}_{1} \mathrm{~B}_{\max }$ simulation and red lines for the $\mathrm{A}_{1} \mathrm{~B}_{\min }$ simulation.

here. The IWP increases and ICNC decreases from winter to summer as the temperatures are higher. As again the increase in IWP is the dominant process, the optical depth increases from winter to summer.

In the dry simulations of the winter months the vertical velocity is higher in A1B9. As here the influence of the additional moisture in the future climate is not taken into account, the stratification is more stable in A1B9 followed by higher vertical velocities. Therefore the ICNC increases for A1B0 despite the higher temperatures. This means that in this case the dynamical changes start to dominate. Together with an increased IWP the optical depths is higher in the A1B9 simulation. However, for the summer months, a reduction in the vertical velocity followed by a strong reduction in the ICNC concentration can be seen. Here, the increased IWP cannot compensate this reduction and the optical depth decreases from the present to a future climate.

\subsection{North America: linear flow regime}

Figure 14 shows the resulting flow regime for the moist simulations initialized with the IPCC profiles for North America after $t=5 \mathrm{~h}$ for the winter month DJF. The moist vertical profiles averaged over JJA for this region show an unstable region in the lower levels. Therefore no gravity waves develop and it is not possible to investigate the effect of a changing climate on the formation of orographic cirrus clouds based on the ECHAM IPCC simulations. We therefore also looked at the results for spring (March, April May) and autumn (September, October, November). For these seasons the same features as for the winter months that are described in this section are seen, and are therefore not shown here.

Again a gravity wave develops which propagates through the whole troposphere. In the Northern Hemisphere the difference in temperature and moisture is more pronounced than in the Southern Hemisphere. Therefore the influence of the additional moisture is stronger. The static stability decreases, as can be seen in the moist Brunt-Väisäla frequency in Fig. 8 (third row) and thus the amplitude and vertical velocity. The maximum vertical velocity in the A1B0 simulation amounts to $1.5 \mathrm{~m} \mathrm{~s}^{-1}$, in the A1B9 simulation to $1.3 \mathrm{~m} \mathrm{~s}^{-1}$. However, the vertical velocities inside the ISSR are only slightly higher. The increase of the vertical wavelength is also much more pronounced than in the southern hemispheric case and the ISSR shifts in a different wave phase. Figure 15 shows the results of IWP, ICNC and optical depth for the Northern Hemisphere.

The orographic cloud again develops above the mountain top and has a horizontal extent of more than $150 \mathrm{~km}$. In this case it can be seen that the ISSR shifts in a different position in the wave phase as in the A1B9 simulation a leeward shift of the formation region of the cloud can be seen. Again, the dominant process is the strong increase in IWP from $6.7 \mathrm{~g} \mathrm{~m}^{-2}$ to $9.4 \mathrm{~g} \mathrm{~m}^{-2}$ under the assumption of a constant relative humidity in a warmer climate. The reduction in ICNC is more pronounced than in the southern hemispheric case. First, there is a slight decrease in the vertical velocities occuring inside the ISSR and second, the warmer temperatures in a changing climate lead to a faster growth rate. As the temperature in a height of $8000 \mathrm{~m}$ increases from $219 \mathrm{~K}$ to $222 \mathrm{~K}$ the crystals grow faster and less crystals can be formed. The difference in the growth rates is more pronounced in this cold temperature range than in the warmer southern hemispheric case and the reduction of the ICNC is more pronounced. However, the strong increase in IWP still dominates the reduction in ICNC and the resulting optical depth of the cloud is higher in the A1B9 simulation.

In order to estimate the uncertainties in the predicted warming we again made some additional simulations where we used the maximum and minimum temperature changes 
predicted for the years 2090-2099. As the ECHAM A1B run predicts an increase of surface temperature of $+4.5 \mathrm{~K}$ we added/subtracted $+1.3 /-2.9 \mathrm{~K}$ from the ECHAM temperature profile $T(z)_{\mathrm{A} 1 \mathrm{~B} 9}$, based on the regional climate projections (Christensen et al., 2007). Again, the stability stays the same. The results of this simulations can be seen in Fig. 15.

Due to the increase in vertical wavelength the air first undergoes a stronger downdraft in the A1B9 simulation before it is lifted. Thus, the net lifting is smaller in A1B9 compared to A1B0 and the formation of the cloud is shifted downwind. The temperatures inside the ISSR amount to $T_{\mathrm{A} 1 \mathrm{~B} 0}=219.5 \mathrm{~K}, T_{\mathrm{A} 1 \mathrm{~B} 9}=222.9 \mathrm{~K}, T_{\mathrm{A} 1 \mathrm{~B} \min }=221.1 \mathrm{~K}$ and $T_{\mathrm{A} 1 \mathrm{Bmax}}=225.4 \mathrm{~K}$. The increase in temperature inside the ISSR from $\mathrm{A} 1 \mathrm{~B} 0$ to $\mathrm{A} 1 \mathrm{~B}_{\min }$ is not much pronounced and the increase in IWP from $6.7 \mathrm{~g} \mathrm{~m}^{-2}$ to $7.2 \mathrm{~g} \mathrm{~m}^{-2}$ is rather weak. Therefore, the resulting optical depth for the $\mathrm{A}_{1} \mathrm{~B}_{\min }$ simulation is only slightly higher than in A1B0. When the temperature is increased further, IWP increases strongly and ICNC decreases. For these cases, the increase in IWP again strongly dominates over the decrease in ICNC and the resulting cloud is optically thicker in a future climate. These simulations combine the two effects of warmer temperatures and a shift in the wave phase, also described in the idealized simulations. A warmer temperature does not necessarily lead to more ice water content. It also depends strongly on the position of the ISSR in the wave phase. Additionally, the reduction of the ICNC can be very strong in cases where the vertical velocities in the ISSR decrease. Therefore, the resulting optical depth is not necessarily higher if dynamics dominate over the thermodynamical features.

The results of the dry simulations for the winter months show an increased vertical velocity in the A1B9 simulation which is mainly caused by the changes in the wind speed. As an increased vertical velocity and a higher temperature counteract for the process of ice nucleation, the ICNC nearly stays the same for both simulations. As the IWP increases for A1B9, the optical depth is also higher. If in the calculation of the Brunt-Väisäla-frequency the moisture is not taken into account, the profile is stable also during the North American summer months and simulations for this case have been performed as well. The results show an increased ICNC caused by changes in the flow regime and an increased IWP followed by an increased optical depth for A1B9 (not shown).

\subsection{North America: hydraulic jump}

For the North American case we also changed the flow regime by increasing the height of the mountain from $600 \mathrm{~m}$ to $1850 \mathrm{~m}$ in order to obtain a non-linear flow regime. The resulting flow is shown in Fig. 16.

In this case the changes in the flow regime are more pronounced than in the South American case. After a spinup time of $3 \mathrm{~h}$ a reasonably stable flow regime develops. The decrease in stability leads to a slight increase in vertical wavelength and to a weak damping of the maximum vertical ve- locity. The time evolution of the flow (not shown here) shows an increased vertical velocity in the first updraft region from A1B0 to A1B9 and a decrease in vertical velocity in the second updraft region inside the ISSR. This feature is caused by the increase in vertical wavelength. In order to assess the changes in the optical properties of the cloud, we again show the time development of the optical depth in figure 17.

The resulting optical depth does not show a strong increase as in the South American case. This behavior can be explained with the simulated mean ICNC and IWP shown in Fig. 18.

The IWP increases from A1B0 to A1B9 in the first updraft region, however, in the second updraft region, the IWP decreases. ICNC increases from A1B0 to A1B9 for the first updraft region, although there is a strong increase in temperature which would lead to a decrease in ICNC. However, the dynamical changes are strong enough to overcompensate this effect and the higher vertical velocity in the first updraft region leads to an increase in ICNC. In the second updraft region, we have a decrease in vertical velocity from A1B0 to A1B9 followed by a strong reduction in ICNC and IWP. Therefore, the resulting optical depth is increased in the first updraft region and decreased in the second updraft region. Here, dynamics strongly influence the microphysical properties of the cloud and nearly offset the thermodynamical changes. The optical depth averaged over the whole cloud from $3-10 \mathrm{~h}$ increases $\sim 15 \%$ from 0.57 for A1B0 to 0.66 for A1B9.

The dry simulation of the winter months shows a slightly increased vertical velocity due to changes in the flow regime. This leads to an increased ICNC. Thus again the dynamical changes dominate the influence of the higher temperatures on the ice crystal number concentration. The IWP increases as well for A1B9 followed by an increased optical depth. We also looked at the results for the summer months for this dry simulation. Here the vertical velocity is much lower for A1B9 again followed by a strong decrease in ICNC. The increase in IWP is however not strong enough to compensate the ICNC reduction leading to a decreased optical depth for A1B9.

In Tables 1 and 2 the results of the IWP, ICNC and optical depth for all simulations (moist and dry) initialized with the IPCC profiles are summarized.

As can be seen from these tables, all moist simulations show an enhanced optical depth of the clouds in a future climate. The increase in IWP dominates in all cases over the decrease in ICNC. Thus, the dynamical changes are less important than the thermodynamical changes. This effect is more pronounced for the non-linear flow regimes where a strong increase of $17.2 \%, 15.6 \%$ and $15.7 \%$ is simulated. For the dry simulations a different picture shows up. Especially for South America, the dynamical changes start to dominate and a reduced optical depth for the future climate is simulated. For North America most of the simulations also show an increased optical depth for A1B9. 

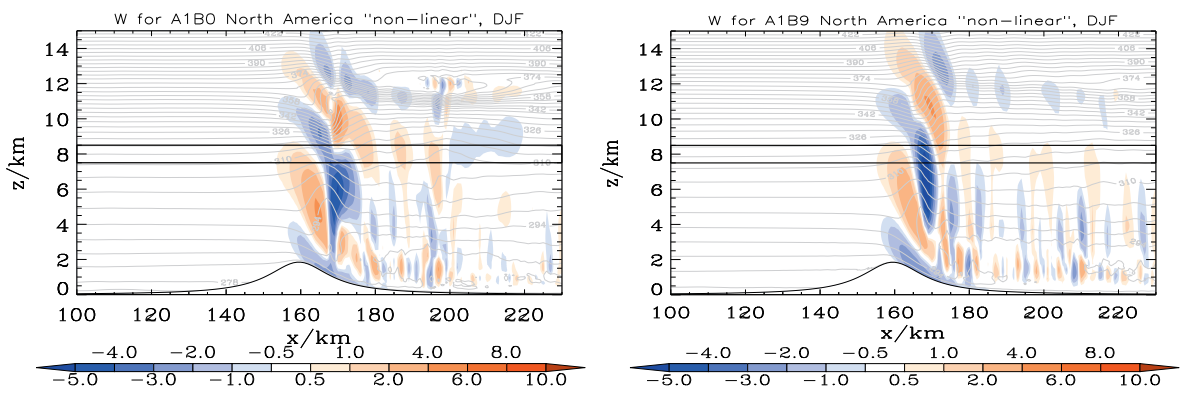

Fig. 16. Flow regime for North America after $t=10 \mathrm{~h}$ for the initial profiles of A1B0 (right) and A1B9 (left). Grey lines denote the lines of potential temperature, colors indicate the vertical velocity. The black box shows the initial position of the supersaturated layer.
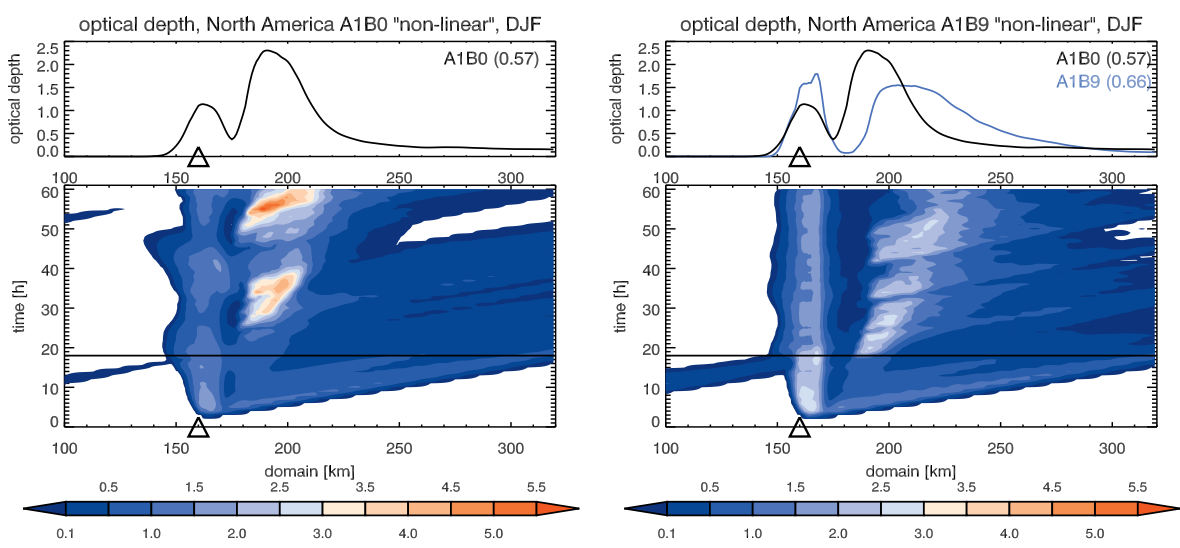

Fig. 17. Time development of the optical depth for the A1B0 (left) and A1B9 (right) simulations. The triangle denotes the top of the mountain, and the black line shows the point in time when the flow becomes reasonably stable. The upper panel shows the time averaged optical depth from 3-10 h. In the upper right panel we also show the time averaged optical depth for the A1B0 simulation for a better comparison.

\section{Summary and discussion}

The 2-dimensional non-hydrostatic model EULAG has been used to investigate the formation of orographic cirrus clouds in a changing climate. Therefore, different simulations with a detailed cloud microphysics have been carried out. To show the model's capability to represent orographic cirrus clouds and to produce realistic results, the INCA case was simulated and compared to measurements. Second, some key parameters which determine the microphysical properties of the developing cloud, like the initial relative humidity, the temperature inside the ISSR and the shift of the position of the ISSR in the vertical wave phase have been investigated with idealized simulations and thirdly, idealized simulations initialized with the IPCC A1B profiles for the beginning and end of the century calculated with the ECHAM model have been carried out.

The comparison with the INCA measurements shows a very good agreement. Although the simulation is only 2dimensional the simulated and measured distributions of ver- tical velocity, ice water content and ice crystal number concentration agree very well.

The idealized simulations show that one important factor which determines the optical depth is the temperature inside the ISSR which determines how much water vapor is available for the formation of ice when a constant relative humidity is assumed. The strong increase in IWP with increasing temperature dominates the reduction of ICNC and the mean optical depth increases. However, in the idealized simulations the increase in temperature is very strong $(10 \mathrm{~K})$ such that the crystals grow very large and start to sediment. This leads to a decrease of the mean optical depth for the warmest temperature and highest initial RHi as the horizontal extent of the cloud and the IWP is reduced. Additionally, the position of the ISSR in the vertical wave phase has a strong influence on the microphysical properties. It could be shown that when the ISSR is shifted to a lower position where the vertical velocities are smaller, the resulting IWP and optical depth is much smaller than for the reference case although the initial RHi is the same and much more water vapor is 
Table 1. ICNC, IWP and optical depth averaged over the whole cloud for all moist simulations initialized with the IPCC profiles. Values in brackets denote the percental change compared to the associated A1B0 run.

\begin{tabular}{|c|c|c|c|}
\hline \multicolumn{4}{|l|}{ Moist simulations } \\
\hline South America & $\operatorname{ICNC}\left[10^{9} \mathrm{~m}^{-2}\right]$ & IWP $\left[\mathrm{g} \mathrm{m}^{-2}\right]$ & optical depth \\
\hline A1B0 - linear, winter & 1.25 & 10.1 & 1.84 \\
\hline A1B9 - linear, winter & $0.87(-30 \%)$ & $13.5(+33 \%)$ & $1.93(+5 \%)$ \\
\hline $\mathrm{A}_{1} \mathrm{~B}_{\min }$ - linear, winter & $0.92(-26 \%)$ & $13.1(+29 \%)$ & $1.94(+5 \%)$ \\
\hline $\mathrm{A} 1 \mathrm{~B}_{\max }$ - linear, winter & $0.71(-43 \%)$ & $15.1(+49 \%)$ & $1.92(+4 \%)$ \\
\hline A1B0 - non-linear, winter & 5.2 & 16.1 & 4.29 \\
\hline A1B9 - non-linear, winter & $4.5(-13 \%)$ & $22.8(+41 \%)$ & $5.03(+17 \%)$ \\
\hline A1B0 - linear, summer & 0.01 & 1.7 & 0.08 \\
\hline A1B9 - linear, summer & $0.09(+800 \%)$ & $13.7(+705 \%)$ & $0.84(+950 \%)$ \\
\hline $\mathrm{A}^{1} \mathrm{~B}_{\min }$ - linear, summer & $0.12(+1100 \%)$ & $15.3(+800 \%)$ & $0.97(+1112 \%)$ \\
\hline $\mathrm{A}_{1} \mathrm{~B}_{\max }$ - linear, summer & $0.12(+1100 \%)$ & $17.1(+905 \%)$ & $0.98(+1125 \%)$ \\
\hline A1B0 - non-linear, summer & 4.5 & 31.1 & 6.08 \\
\hline A1B9 - non-linear, summer & $3.5(-22 \%)$ & $44.2(+42 \%)$ & $7.03(+16 \%)$ \\
\hline North America & $\operatorname{ICNC}\left[10^{9} \mathrm{~m}^{-2}\right]$ & IWP $\left[\mathrm{g} \mathrm{m}^{-2}\right]$ & optical depth \\
\hline A1B0 - linear, winter & 1.5 & 6.7 & 1.53 \\
\hline A1B9 - linear, winter & $1.0(-33 \%)$ & $9.4(+40 \%)$ & $1.66(+8 \%)$ \\
\hline $\mathrm{A}_{1} \mathrm{~B}_{\min }-$ linear, winter & $1.4(-6 \%)$ & $7.2(+7 \%)$ & $1.57(+3 \%)$ \\
\hline $\mathrm{A}_{1} \mathrm{~B}_{\max }$ - linear, winter & $0.9(-40 \%)$ & $10.6(+58 \%)$ & $1.71(+12 \%)$ \\
\hline A1B0 - non-linear, winter & 0.28 & 5.2 & 0.57 \\
\hline A1B9 - non-linear, winter & $0.20(-28 \%)$ & $6.6(+26 \%)$ & $0.66(+16 \%)$ \\
\hline
\end{tabular}

icnc burden, North America, "non-linear", DJF

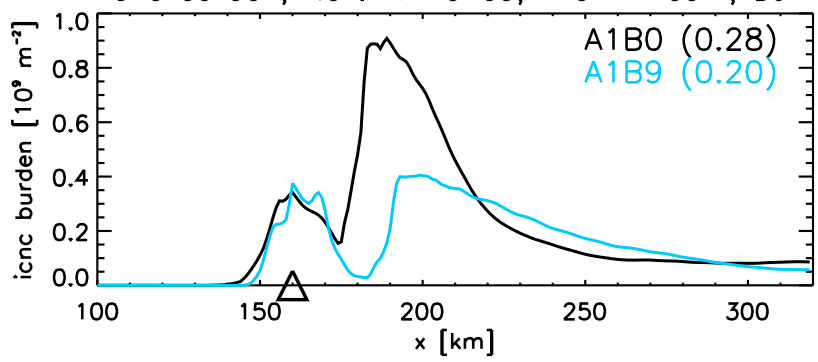

ice water path, North America, "non-linear", DJF

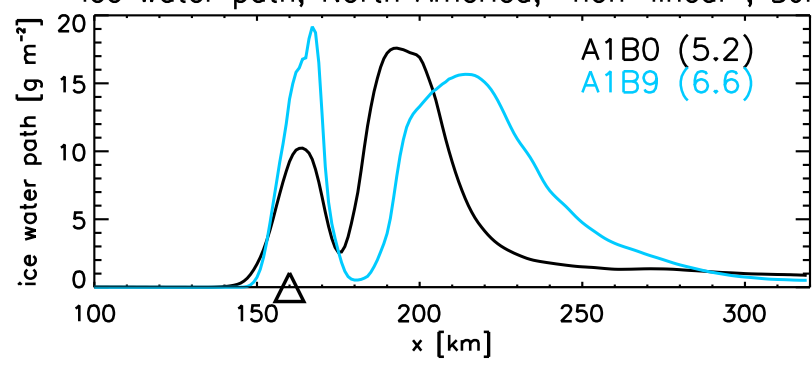

Fig. 18. ICNC and IWP for the simulations A1B0 and A1B9 averaged over $t=3-10 \mathrm{~h}$ for North America. The triangle denotes the tip of the mountain. available at the warmer temperatures in the lower layer. The layer which is shifted to a higher position and thus lower temperatures shows a strong increase in ICNC. The optical depth for the highest layer is therefore higher than for the lowest layer although the IWP is much less. If the temperature inside the ISSR is increased due to a shift of the initial temperature profile or due to a change of the height of the ISSR, the resulting IWP and optical depth for the temperature shift are much higher than for the change of the height as the ISSR occurs in a different phase of the wave. In general, when the temperature increases at a constant relative humidity, the following increase in IWP and optical depth is the dominant process. The decrease of ICNC which would lead to a decrease in optical depth cannot compensate the effect of an increased IWP.

For the simulations with the IPCC profiles it seems that under the assumption of a constant relative humidity in a changing climate (Held and Soden, 2000), the increase in IWP due to the increase in humidity and temperature is the dominant effect. All moist simulations for the linear as well as the non-linear flow regime for both seasons show the same behavior with an increase in optical depth for the end of the century. However, in the North American case the optical depth increases very slightly for the $\mathrm{A}_{1} \mathrm{~B}_{\min }$ simulation as the increase in moisture and the following change in the flow 
Table 2. ICNC, IWP and optical depth averaged over the whole cloud for all dry simulations initialized with the IPCC profiles. Values in brackets denote the percental change compared to the associated A1B0 run.

\begin{tabular}{|c|c|c|c|}
\hline \multicolumn{4}{|l|}{ Dry simulations } \\
\hline South America & $\operatorname{ICNC}\left[10^{9} \mathrm{~m}^{-2}\right]$ & IWP $\left[\mathrm{g} \mathrm{m}^{-2}\right]$ & optical depth \\
\hline A1B0 - linear, winter & 0.5 & 8.4 & 1.14 \\
\hline A1B9 - linear, winter & $0.3(-40 \%)$ & $10.2(+22 \%)$ & $1.04(-9 \%)$ \\
\hline A1B0 - non-linear, winter & 11.5 & 13.9 & 4.95 \\
\hline A1B9 - non-linear, winter & $20.7(+80 \%)$ & $30(+116 \%)$ & $9.94(+101 \%)$ \\
\hline A1B0 - linear, summer & 0.6 & 16.5 & 1.93 \\
\hline A1B9 - linear, summer & $0.2(-67 \%)$ & $17.9(+9 \%)$ & $1.36(-30 \%)$ \\
\hline A1B0 - non-linear, summer & 12.5 & 21 & 6.92 \\
\hline A1B9 - non-linear, summer & $3.6(-71 \%)$ & $31.2(+48 \%)$ & $5.67(-18 \%)$ \\
\hline North America & $\operatorname{ICNC}\left[10^{9} \mathrm{~m}^{-2}\right]$ & IWP $\left[\mathrm{g} \mathrm{m}^{-2}\right]$ & optical depth \\
\hline A1B0 - linear, winter & 1.1 & 7.5 & 1.48 \\
\hline A1B9 - linear, winter & $1.09(-1 \%)$ & $10.9(+46 \%)$ & $1.86(+26 \%)$ \\
\hline A1B0 - non-linear, winter & 5.5 & 6.8 & 2.19 \\
\hline A1B9 - non-linear, winter & $6.9(+25 \%)$ & $12.1(+78 \%)$ & $3.73(+70 \%)$ \\
\hline A1B0 - linear, summer & 0.05 & 4.8 & 0.29 \\
\hline A1B9 - linear, summer & $0.14(+180 \%)$ & $13.8(+187 \%)$ & $0.96(+231 \%)$ \\
\hline A1B0 - non-linear, summer & 1.2 & 6.5 & 1.18 \\
\hline A1B9 - non-linear, summer & $0.3(-75 \%)$ & $8.8(+35 \%)$ & $0.77(-34 \%)$ \\
\hline
\end{tabular}

regime is much more pronounced and the effect of an increased IWP at constant RHi is not dominant anymore. However, if the temperature increase from A1B0 to A1B9 is large enough the increase in IWP dominates again and the optical depth increases from A1B0 to A1B9. This North American example shows that changes in the dynamics regime can become important and can contribute to changes in the IWP, ICNC and optical depth. In the dry simulations the dynamical changes become important. For South America, most simulations show a decreased optical depth caused by smaller vertical velocities which lead to a strong reduction in the ICNC in A1B9. However, most of the simulations for North America show the same behavior as their corresponding moist simulations. This means that most simulations point into the direction that the increase in IWP is the most dominant effect and that the change in the flow regime and vertical velocities play a secondary role here. All these effects and their influence on the microphysical and optical properties are summarized in Fig. 19.

The predicted increase in temperature in the IPCC simulations are small enough that the reduction of the horizontal extent or lifetime of the cloud due to sedimenting ice crystals does not occur in our simulations. Nevertheless it cannot be ruled out completely.

These simulations only represent first ideas about the behavior of orographic cirrus in a changing climate. In order to

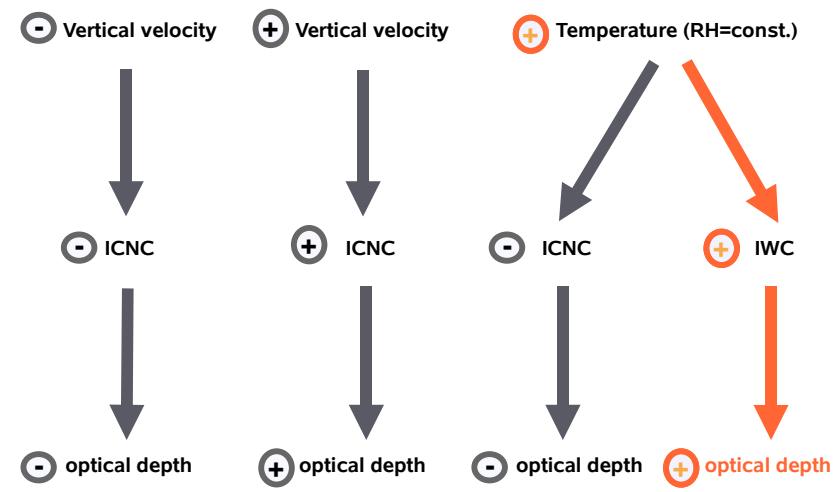

Fig. 19. Schematic of possible dynamical and thermodynamical changes in orographic cirrus clouds in the future climate and the following changes in microphysical and optical properties. The effect dominating most of the simulations is highlighted in red.

make more quantitative conclusions additional simulations are necessary. The use of mean vertical profiles for initializing the model implies some problems as the change in microphysical properties generated by the mean flow does not equal the mean change in microphysical properties which would be generated by all different flow regimes occuring in ten years. Additionally, the assumption of condensation 
occuring everywhere in the moist simulations and neglecting it in the dry simulations represent only the two extreme cases whereas in many cases the reality might be somewhere in between. Nevertheless, we could show that we can expect an influence of the changing climate on the microphysical and optical properties of orographic cirrus clouds. As the cirrus cloud cover over continents which are formed due to orographic forcing is quite substantial (Dean et al., 2005), a strong influence on the radiative budget can be expected. In order to make reliable predictions of the change in cirrus cloud cover and microphysical properties the change in atmospheric stability caused by an increased moisture and its influence on the flow regime as well as the change of the temperature and water vapor in the upper troposphere have to be considered.

Acknowledgements. We thank the European Centre for MediumRange Weather Forecasts (ECMWF) for computing time, Andreas Minikin (DLR) and Jean-Francois Gayet (LMP) for providing the INCA data and two anonymous reviewers for helpful discussions. This work contributes to the TH-project "Orographic cirrus clouds in the climate model ECHAM5" (grant: TH-18 06-1) supported by ETH Research Fonds. This work was partly supported by the European Commission within the framework of the Marie Curie Fellowship "Impact of mesoscale dynamics and aerosols on the life cycle of cirrus clouds" (IMDALCC).

Edited by: T. Koop

\section{References}

Bögel, W. and Baumann, R.: Test and Calibration of the DLR Falcon Wind Measuring System by Maneuvers, J. Atmos. Ocean. Tech., 8, 5-18, 1991.

Chen, T., Rossow, W., and Zhang, Y.: Radiative effects of cloudtype variations, J. Climate, 13, 264-286, 2000.

Christensen, J., Hewitson, B., Busuioc, A., Chen, A., Gao, X., Held, I., Jones, R., Kolli, R., Kwon, W.-T., Laprise, R., Magana Rueda, V., Mearns, L., Menendez, C., Raisanen, J., Rinke, A., Sarr, A., and Whetton, P.: Climate Change 2007: The Physical Science Basis. Contributing of Working Group I to the Fourth Assessment Report of the Intergovernmental Panel on Climate Change, chap. Regional Climate Projections, Cambridge University Press,Cambridge, United Kingdom and New York, NY, USA, 2007.

Clark, T. and Farley, R.: Severe downslope windstorm calculations in two and three spatial dimensions using anelastic interactive grid nesting: A possible mechanism for gustiness, J. Atmos. Sci., 41, 329-350, 1984.

Dean, S., Lawrence, B., Grainger, R., and Heuff, D.: Orographic cloud in a GCM: the missing cirrus, Clim. Dyn., 24, 771-780, 2005.

Dörnbrack, A.: Turbulent mixing by breaking gravity waves, J. Fluid Mech., 375, 113-141, 1998.

Durran, D. and Klemp, J.: A compressible model for the simulation of moist mountain waves, Mon. Wea. Rev., 111, 2341-2361, 1983.
Ebert, E. and Curry, J.: A parameterization of ice cloud optical properties for climate models, J. Geophys. Res., 97 (D4), 38313836, 1992.

Fu, Q. and Liou, K.: Parameterization of the Radiative Properties of Cirrus Clouds, J. Atmos. Sci., 50, 2008-2025, 1992.

Fusina, F., Spichtinger, P., and Lohmann, U.: The impact of ice supersaturated regions and thin cirrus on radiation in the mid latitudes, J. Geophys. Res., 112, D24S14, doi:10.1029/ 2007JD008449, 2007.

Gayet, J.-F., Auriol, F., Minikin, A., Ström, J., Seifert, M., Krejci, R., Petzold, A., Febvre, G., and Schumann, U.: Quantitative measurement of the microphysical and optical properties of cirrus clouds with four different in-situ probes: Evidence of small ice crystals, Geophys. Res. Lett., 29 (24), 2230, doi: 10.1029/2001GL014342, 2002.

Gayet, J.-F., Ovarlez, J., Shcherbakov, V., Ström, J., Schumann, U., Minikin, A., Auriol, F., and Petzold, A.: Cirrus cloud microphysical and optical properties at southern and northern midlatitudes during the INCA experiment, J. Geophys. Res., 109, D20206, doi:10.1029/2004JD004803, 2004.

Gayet, J.-F., Shcherbakov, V., Mannstein, H., Minikin, A., Schumann, U., Ström, J., Petzold, A., Ovarlez, J., and Immler, F. Microphysical and optical properties of midlatitude cirrus clouds observed in the southern hemisphere during INCA, Q. J. R. Meteorol. Soc., 132, 2719-2748, 2006.

Grabowski, W. and Smolarkiewicz, P.: A multiscale anelastic model for meteorological research, Mon. Weather Rev., 130, 939-956, 2002.

Hastings, D., Dunbar, P., Elphingstone, G. M., Bootz, M., Murakami, H., Maruyama, H., Masaharu, H., Holland, P., Payne, J., Bryant, N., Logan, T., Muller, J.-P.and Schreier, G., and MacDonald, J.: The Global Land One-kilometer Base Elevation (GLOBE) Digital Elevation Model, Version 1.0., http://www.ngdc.noaa.gov/mgg/topo/globe.html, 1999.

Held, I. and Soden, B.: Water vapor feedback and global warming, Annu. Rev. Energy Environ., 25, 441-475, 2000.

Jiang, Q.: Moist dynamics and orographic precipitation, Tellus, 55A, 301-316, 2003.

Joos, H., Spichtinger, P., Lohmann, U., Gayet, J.-F., and Minikin, A.: Orographic cirrus in the global climate model ECHAM5, J. Geophys. Res., 113, D18205, doi:10.1029/2007JD009605, 2008.

Kärcher, B. and Lohmann, U.: A parameterization of cirrus cloud formation: Homogeneous freezing of supercooled aerosols, J. Geophys. Res., 107 (D2), doi:10.1029/2001JD000470, 2002.

Kärcher, B. and Ström, J.: The roles of dynamical variability and aerosols in cirrus cloud formation, Atmos. Chem. Phys., 3, 823 838, 2003, http://www.atmos-chem-phys.net/3/823/2003/.

Koop, T., Luo, B., Tsias, A., and Peter, T.: Water activity as the determinant for homogeneous ice nucleation in aqueous solutions, Nature, 406, 611-614, 2000.

Meehl, G., Stocker, T., Collins, W., Friedlingstein, P., Gaye, A., Gregory, J., Kitoh, A., Knutti, R., Murphy, J., Noda, A., Raper, S., Watterson, I., Weaver, A., and Zhao, Z.-C.: Climate Change 2007: The physical Science Basis. Contribution of Working Group I to the Fourth Assessment Report of the Intergovernmental Panel on Climate Change, chap. Global Climate Projections, Cambridge University Press,Cambridge, United Kingdom and New York, NY, USA, 2007.

Noone, K., Ogran, J., Heintzenberg, J., Charlson, R., and Covert, 
D.: Design and calibration of a counterflow virtual impactor for sampling of atmospheric fog and cloud droplets, Aerosol Sci. Technol., 8, 235-244, 1993.

Penner, J., Chen, Y., Wang, M., and Liu, X.: Possible influence of anthropogenic aerosols on cirrus clouds and anthropogenic forcing, Atmos. Chem. Phys., 9, 879-896, 2009,

http://www.atmos-chem-phys.net/9/879/2009/.

Prusa, J., Smolarkiewicz, P., and Wyszogrodzki, A.: EULAG, a computational model for multiscale flows, Computers and fluids, 37, 1193-1207, 2008.

Smolarkiewicz, P. and Margolin, L.: On Forward-in-Time Differencing for Fluids: an Eulerian/Semi-Lagrangian NonHydrostatic Model for Stratified Flows, Atmosphere-Ocean, 35, 127-152, 1997.

Spichtinger, P. and Gierens, K.: Modelling of Cirrus Clouds. Part 1a: Model description and validation, Atmos. Chem. Phys., 9, 685-706, 2009, http://www.atmos-chem-phys.net/9/685/2009/.
Spichtinger, P., Gierens, K., and Dörnbrack, A.: Formation of ice supersaturation by mesoscale gravity waves, Atmos. Chem. Phys., 5, 1243-1255, 2005a.

Spichtinger, P., Gierens, K., and Wernli, H.: A case study on the formation and evolution of ice supersaturation in the vicinity of a warm conveyor belt's outflow region, Atmos. Chem. Phys., 5, 1243-1255, 2005b.

Zhang, M., Lin, W., Klein, S., Bacmeister, J., Bony, S., Cederwall, R., DelGenio, A., Hack, J., Loeb, N., Lohmann, U., Minnis, P., Musat, I., Pincus, R., Stier, P., Suarez, M., Webb, M., Wu, J., Xie, S., Yao, M., and Zhang, J.: Comparing clouds and their seasonal variations in 10 atmospheric general circulation models with satellite measurements, J. Geophys.Res., 110, D15S02, doi: 10.1029/2004JD005021, 2005. 